\title{
Variação espacial da estrutura da comunidade arbórea de um fragmento de floresta semidecídua em Piedade do Rio Grande, MG, Brasil
}

\author{
WARLEY A. C. CARVALHO ${ }^{1}$, ARY TEIXEIRA DE OLIVEIRA FILHO ${ }^{1,3}$, \\ MARCO A. L. FONTES ${ }^{1}$ e NILTON CURI ${ }^{2}$
}

(recebido: 21 de janeiro de 2005; aceito: 10 de maio de 2007)

\begin{abstract}
Spatial variation of tree community structure in a fragment of tropical semideciduous forest in Piedade do Rio Grande, Minas Gerais State, Brazil). A survey of the tree community, topography and soils of a fragment of tropical semideciduous forest was carried out with the objective of assessing alleged correlations between the variations in community structure and species composition and variations in edge effect and soil water regime and chemical fertility. The fragment (30 ha of area) is situated at $21^{\circ} 29^{\prime} 03$ ' S and 44 06'05”'W, in Piedade do Rio Grande, Minas Gerais State, SE Brazil. A topographic survey and a detailed soil classification were accomplished in the forest area. Individual trees with diameter at breast height $(\mathrm{dbh}) \geq 5 \mathrm{~cm}$ were sampled in 30 plots with $400 \mathrm{~m}^{2}, 12$ of which were placed at the forest edges and 18 in the forest interior. Samples of surface soil ( $0-20 \mathrm{~cm}$ of depth) were collected from each plot for analyses of chemical and textural properties. The survey registered 1,778 individuals belonging to 174 species, and three soil subgroups. Tree density and species diversity was higher in edge than in interior plots, but no difference was found for basal area. An interactive canonical correspondence analysis (CCA) of the patterns emerging from the environmental variables, spatial variables and species abundances indicated that these are distributed in the fragment under a strong influence of spatial proximity, edge effects, soil water regime expressed by topographical elevation and soil chemical fertility expressed by the bases saturation.
\end{abstract}

Key words - edge effect, environment-vegetation relationship, forest fragmentation, multivariate analysis, tree community structure, tropical semideciduous forest

RESUMO - (Variação espacial da estrutura da comunidade arbórea de um fragmento de Floresta Semidecídua em Piedade do Rio Grande, MG, Brasil). Foi realizado um levantamento da comunidade arbórea, do relevo e solos de um fragmento de floresta semidecídua com objetivo de verificar as possíveis correlações entre variações da estrutura comunitária e composição de espécies e variações do efeito borda e do regime de água e fertilidade dos solos. O fragmento possui 30 ha, com coordenadas $21^{\circ} 29^{\prime} 03^{\prime} \mathrm{S}$

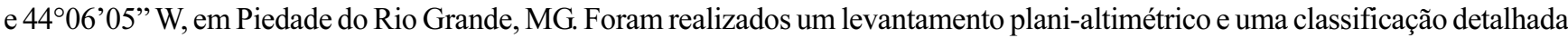
dos solos da floresta. Indivíduos arbóreos com diâmetro à altura do peito $\geq 5 \mathrm{~cm}$ foram amostrados em 30 parcelas de $400 \mathrm{~m}^{2}$, sendo 12 parcelas situadas na borda do fragmento e 18 no interior do fragmento. Amostras do solo superficial $(0$ a $20 \mathrm{~cm}$ de profundidade) foram coletadas nas parcelas para análises das propriedades químicas e texturais. Foram registrados 1.778 indivíduos pertencentes a 174 espécies e três subgrupos de solos. A densidade de árvores e a diversidade de espécies foram mais elevadas nas parcelas de borda que nas de interior, mas nenhuma diferença foi detectada para área basal. Uma análise de correspondência canônica interativa dos padrões emergentes das variáveis ambientais, variáveis espaciais e abundância das espécies indicou que estas se distribuem no fragmento sob forte influência da proximidade espacial, do efeito borda, do regime de água do solo expresso pela cota topográfica e da fertilidade química dos solos expressa pela saturação por bases.

Palavras-chave - análise multivariada, correlação ambiente-vegetação, efeito borda, estrutura da comunidade arbórea, floresta tropical semidecídua, florística, fragmentação florestal

\section{Introdução}

Nas últimas décadas foi crescente o avanço nos estudos descritivos de comunidades florestais tropicais em todo mundo, de imprescindível importância para a conservação da biodiversidade. No Brasil, estas iniciativas têm sido cada vez mais encorajadas devido

1. Universidade Federal de Lavras, Departamento de Ciências Florestais, 37200-000 Lavras, MG.

2. Universidade Federal de Lavras, Departamento de Ciências do Solo, 37200-000 Lavras, MG.

3. Autor para correspondência: ary@ufla.br ao processo desordenado de ocupação do solo que, nas mais diversas regiões, têm transformado extensões florestais contínuas em fragmentos isolados (Botrel et al. 2002). Sendo o quinto maior país em extensão territorial, o Brasil apresenta grande variação em clima e solo, proporcionando vegetação variada com alta diversidade de habitats. O Estado de Minas Gerais, em particular, possui a maior variedade de formações vegetais do país, explicada por sua extensão e diversidade de condições geológicas, topográficas e climáticas. Porém, apesar da crescente constatação da necessidade da conservação dos recursos naturais, a cobertura vegetal primitiva foi reduzida a fragmentos 
esparsos recobrindo cerca de apenas $2 \%$ do território mineiro (CETEC 1983). A região do Alto Rio Grande, sul de Minas Gerais, encontra-se com sua cobertura vegetal reduzida a fragmentos de florestas e cerrados, a maioria deles muito perturbada por fogo, pecuária extensiva ou retirada seletiva de madeira para fins múltiplos (Botrel et al. 2002). As florestas semidecíduas desta região foram particularmente alteradas e reduzidas por conseqüência de quase sempre ocuparem os solos mais férteis e úmidos, mais propícios à agropecuária (Oliveira Filho et al. 1994).

A fragmentação florestal ocorre, na maioria das vezes, devido à substituição de parte da floresta por pastagens ou atividades agrícolas. As pressões antrópicas sobre estas fisionomias têm graves conseqüências, principalmente numa das mais antigas regiões de ocupação por colonizadores europeus e seus escravos africanos, como é a região do Alto Rio Grande. Portanto, é extremamente importante ampliar o conhecimento sobre a diversidade biológica remanescente nos atuais fragmentos florestais da região e sobre a organização espacial das comunidades vegetais e suas respostas à fragmentação da paisagem. Este conhecimento poderá gerar subsídios para o manejo e a conservação dos recursos naturais no longo prazo.

O presente trabalho foi desenvolvido em uma comunidade arbórea de um fragmento de floresta semidecídua no Município de Piedade do Rio Grande, sul de Minas Gerais. O objetivo foi verificar as possíveis correlações entre as variações da estrutura, da diversidade de espécies e da distribuição espacial das mesmas com a influência da borda do fragmento e de variações do substrato, aqui compreendido como o conjunto de variáveis topográficas e edáficas que determinam o status nutricional mineral e o regime de água dos solos. Também foi avaliada a autocorrelação espacial, ou seja os padrões de distribuição vinculados à mera proximidade entre indivíduos.

\section{Material e métodos}

Foi estudado um remanescente de floresta nativa com área de 30,2 ha, localizado no Município de Piedade do Rio Grande, MG, nas coordenadas $21^{\circ} 29^{\prime} 03^{\prime \prime} \mathrm{S}$ e $44^{\circ} 06^{\prime} 04^{\prime \prime} \mathrm{WG}$ (figura 1). O relevo é acidentado, com declividades entre $25 \mathrm{e}$ $40^{\circ}$ e altitudes variando entre 1.050 e $1.150 \mathrm{~m}$. O embasamento rochoso é o gnaisse granítico. O clima é do tipo $C w b$ de Köppen (mesotérmico com verões brandos e suaves e estiagem de inverno). As médias anuais de precipitação e temperatura são $1.510 \mathrm{~mm}$ e $17,9^{\circ} \mathrm{C}$, respectivamente, valores estes registrados para Barbacena (Brasil 1992), cidade a cerca de $50 \mathrm{~km}$ da área de estudos e altitude de $1.126 \mathrm{~m}$. A vegetação é classificada como floresta semidecídua alto-montana a baixo-montana (segundo Oliveira Filho \& Fontes 2000) ou floresta estacional semidecidual montana (segundo Veloso et al. 1991). Os poucos

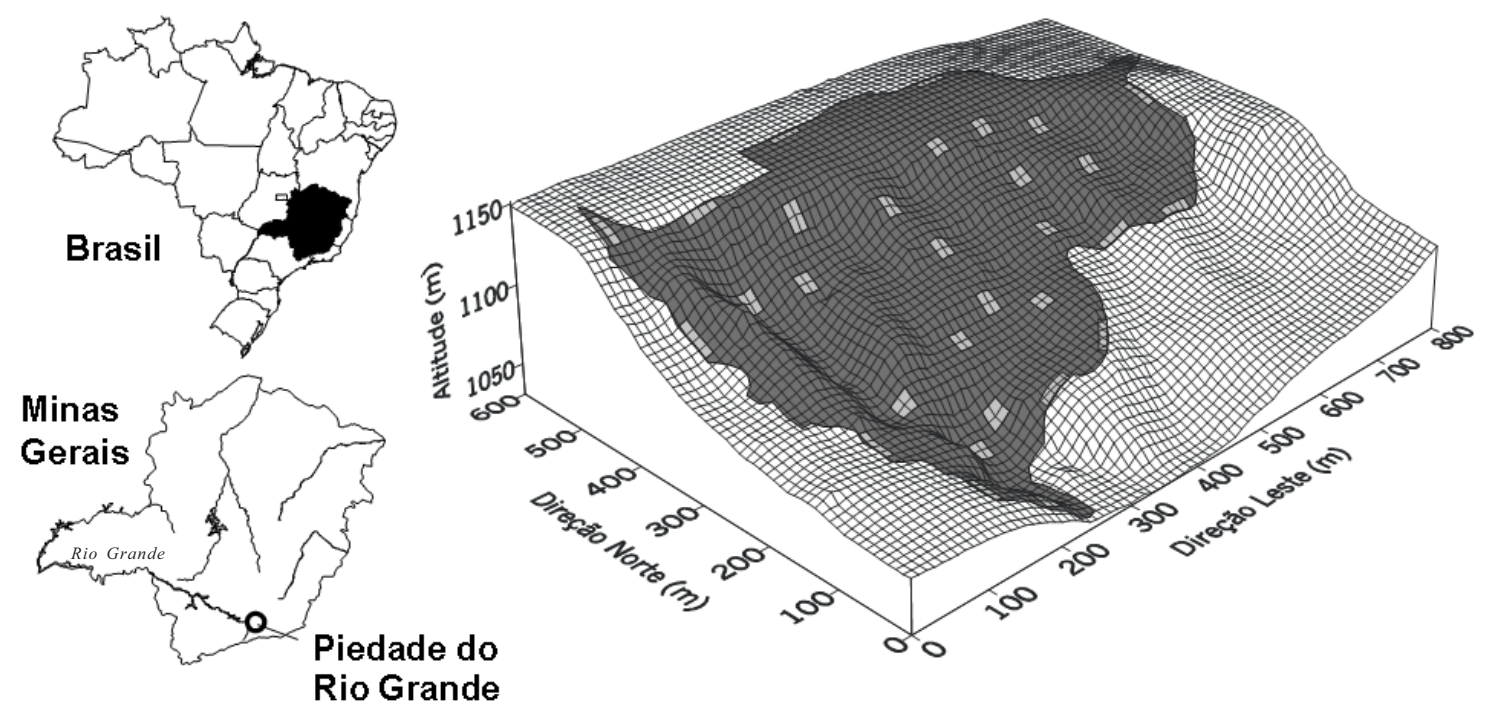

Figura 1. Piedade do Rio Grande no Estado de Minas Gerais, Brasil. Grade de superfície mostrando o relevo do fragmento florestal e a distribuição das 30 parcelas. Espaçamento entre linhas $=10 \mathrm{~m}$.

Figure 1. Piedade do Rio Grande in the State of Minas Gerais, Brazil. Surface grid showing the topography of the forest fragment and the distribution of the 30 plots. Gridline spacing $=10 \mathrm{~m}$. 
indivíduos de Araucaria angustifolia não são suficientes para caracterizar nem mesmo uma transição para florestas ombrófilas mistas. A floresta encontra-se em fase madura pois, segundo levantamento histórico, não houve corte raso ou retirada seletiva de grandes árvores nos últimos 150 anos.

O procedimento amostral foi estratificado e aleatório. A área amostral foi de 1,2 ha, constituída de 30 parcelas de $400 \mathrm{~m}^{2}$ distribuídas aleatoriamente por sorteio sobre ortofotocarta 1:10.000, sendo alocadas 18 parcelas de $20 \times 20 \mathrm{~m}$ no interior do fragmento (estrato Interior) e 13 parcelas de $10 \times 40 \mathrm{~m}$ nas bordas (estrato Borda). A localização das parcelas do Interior foi sorteada entre as coordenadas de uma grade de pontos de $20 \times 20 \mathrm{~m}$ ajustada ao acaso à ortofotocarta. A situação das parcelas de Borda foi sorteada ao longo do perímetro da borda do fragmento e seu lado maior foi justaposto à borda de forma a maximizar a representação deste ambiente. Todos os indivíduos com DAP (diâmetro à altura do peito ou a $1,30 \mathrm{~m}$ de altura) $\geq 5 \mathrm{~cm}$ equivalente a uma circunferência à altura do peito, CAP $\geq 15,71 \mathrm{~cm}$ foram marcados e medidos em circunferência e altura. Indivíduos com caules múltiplos foram medidos quando a raiz da soma dos quadrados dos perímetros era $\geq 15,71 \mathrm{~cm}$, o que implica em uma área basal equivalente (Scolforo \& Mello 2006). Nestes casos, caules CAP $<1 \mathrm{~cm}$ foram desprezados e, quando o resultado do cálculo era duvidoso no campo, o indivíduo era medido e, depois de feitos os cálculos, preservado na planilha ou então eliminado. Não foram incluídos indivíduos mortos e lianas. O levantamento florístico resultou de amostras de material botânico coletadas nos levantamentos das parcelas e em caminhamentos pelo fragmento, em visitas mensais de janeiro de 1999 a outubro de 2000 . O material testemunho encontrase depositado no herbário da Universidade Federal de Lavras (Herbário ESAL). A classificação nas famílias seguiu o sistema APG II (2003).

Para descrição da estrutura das comunidades arbóreas do Interior e da Borda, foram extraídos, para cada espécie em cada estrato amostral, os valores de número de indivíduos, área basal total e número de parcelas onde ocorre. Testes de $t$ de Student para amostras independentes foram empregados para comparar as médias de várias características da comunidade arbórea nas parcelas de Borda e Interior. Os pressupostos de populações independentes, normais e com variâncias iguais foram deliberadamente assumidos para realizar os testes de $t$, pois, de acordo com Zar (1996), “o pesquisador na área biológica não pode (...) ter sempre certeza de que estes pressupostos são corretos. Felizmente, muitos estudos têm mostrado que o teste de $t$ é robusto o bastante para suportar consideráveis desvios de suas premissas teóricas". As variáveis estruturais comparadas foram densidade, área basal, diâmetros médio e máximo e alturas média e máxima. Foram preparadas distribuições de densidade de árvores por classes de diâmetro e altura para as subamostras de Borda e Interior, sendo utilizados intervalos de classe com amplitudes crescentes para compensar o decréscimo da densidade nas classes de tamanho maiores, conforme Botrel et al. (2002). O teste de $t$ também foi empregado para comparar a densidade de árvores em cada classe de diâmetro e altura nos dois estratos amostrais.

Foram calculados, para a amostra total e seus dois estratos, o índice de diversidade de Shannon e a equabilidade de Pielou (Brower \& Zar 1984) e os estimadores jackknife (de primeira e segunda ordem) do total de espécies (Heltsche \& Forrester 1983, Palmer 1991). A densidade de espécies e o índice de Shannon na Borda e Interior foram comparados pelo teste de $t$ para amostras independentes e pelo teste de $t$ de Hutcheson, respectivamente (Zar 1996).

O solo de cada parcela foi classificado segundo o sistema da Embrapa (1999) até o nível de subgrupo ( $4^{\circ}$ nível categórico), incluindo também os agrupamentos texturais e classes de drenagem. No centro de cada parcela, foram coletadas amostras de solo ( 0 a $20 \mathrm{~cm}$ de profundidade), as quais foram levadas ao Laboratório de Análise de Solos do Departamento de Ciências do Solo da UFLA para análises químicas e texturais. Foram obtidas as variáveis: $\mathrm{pH}, \mathrm{P}, \mathrm{K}$, $\mathrm{Ca}^{2+}, \mathrm{Mg}^{2+}, \mathrm{Al}^{3+}$, saturação por bases $(\mathrm{V})$, carbono (C), matéria orgânica (MO) e teores de areia, silte e argila, seguindo o protocolo da Embrapa (1997). Foram comparadas as variáveis químicas e texturais entre os três subgrupos de solos encontrados, por análises de variância complementadas por testes de Tukey-Kramer (Zar 1996). Foi realizado um levantamento planialtimétrico do fragmento que permitiu obter duas variáveis topográficas, cota média e desnível máximo, as quais foram utilizadas como meio de avaliação indireta das variáveis hidrológicas do solo (Oliveira Filho et al. 1994). Para avaliar a influência da borda na distribuição das espécies foi produzido um "fator de borda" para cada parcela, de acordo com o método utilizado por Espírito-Santo et al. (2002) e Souza et al. (2003), onde este é definido pelo comprimento linear do contorno da borda medido entre dois ou mais pontos de intercessão com o perímetro de um círculo cujo raio de $100 \mathrm{~m}$ tem origem no centro da parcela em questão.

Para correlacionar as variações quantitativas das espécies arbóreas nas parcelas com variáveis ambientais e espaciais, foi adotada a análise de correspondência canônica (CCA, ter Braak 1987) executada seguindo o procedimento interativo de Borcard et al. (1992), que exige a preparação de três matrizes. A primeira delas é a matriz das espécies que, no presente caso, consistiu do número de indivíduos (n) por parcela das 46 espécies com 10 ou mais indivíduos na amostra total. Os valores foram transformados em $\ln (n+1)$ para compensar desvios causados pela baixa freqüência dos valores mais elevados (ter Braak 1995). A segunda é a matriz de variáveis ambientais que incluiu todas as variáveis topográficas e edáficas acrescidas do fator borda. A terceira é a matriz de variáveis espaciais que consistiu das coordenadas binárias do centro geométrico das parcelas, $\mathrm{x}$ e $\mathrm{y}$, mais sete variáveis delas derivadas $-\mathrm{x}^{2}, \mathrm{x}^{3}, \mathrm{y}^{2}, \mathrm{y}^{3}, \mathrm{x}^{*} \mathrm{y}, \mathrm{x}^{2 *} \mathrm{y}$ e $\mathrm{x}^{*} \mathrm{y}^{2}$ - seguindo um modelo polinomial proposto por Borcard et al. (1992).

O passo seguinte foi a realização de quatro CCAs relacionando a matriz de espécies com (CCA1) variáveis ambientais, (CCA2) variáveis espaciais, (CCA3) variáveis 
ambientais e co-variáveis espaciais e (CCA4) variáveis espaciais e co-variáveis ambientais. Para tanto, foi utilizado o programa CANOCO 4.5 (ter Braak \& Smilauer 2002). Nas duas primeiras CCAs, foi utilizada a rotina de seleção progressiva de variáveis ambientais associada a testes de permutação de Monte Carlo para verificar significância das mesmas. No caso das variáveis ambientais, apenas três permaneceram - cota, fator borda e saturação por bases - e, no das variáveis espaciais, só duas foram preservadas $-\mathrm{y}^{2} \mathrm{e}$ $\mathrm{y}^{3}$. As mesmas variáveis foram utilizadas nas duas outras CCAs. Testes de permutação Monte Carlo foram aplicados às quatro CCAs e seus resultados foram empregados para estimar a proporção da variação dos dados das espécies que é explicada distintamente pelas variáveis ambientais e espaciais, bem como a proporção explicada indistintamente pelos dois conjuntos de variáveis e a variação remanescente que não é explicável por nenhuma das variáveis em questão.

As três variáveis ambientais foram também utilizadas para analisar a distribuição das abundâncias de cada uma das mesmas 46 espécies nas parcelas. Para comparar as abundâncias entre parcelas de Borda e Interior, foi utilizado o teste de $t$ para amostras independentes e, no caso da cota média e saturação por bases, foram calculadas correlações de Pearson (Zar 1996). Os valores de abundância foram transformados pela função logarítmica porque esta aproximou sua distribuição do modelo normal.

\section{Resultados}

O levantamento florístico geral, que incluiu coletas fora das parcelas, registrou 65 famílias, 156 gêneros e 269 espécies, 174 das quais foram exclusivas das parcelas (tabelas 1 e 3 ). A família Fabaceae destacou-se pela maior riqueza de espécies (26) e gêneros (19), representando $9,7 \%$ do total de espécies registradas. Na segunda posição, as famílias Myrtaceae e Lauraceae apresentaram ambas 21 espécies. Outras famílias expressivas foram: Melastomataceae (15 espécies), Euphorbiaceae, Meliaceae e Rubiaceae (as três com 10 espécies). Na Borda, as cinco espécies de maior área basal foram Piptadenia gonoacantha, Machaerium villosum, Croton floribundus, Bauhinia forficata e Araucaria angustifolia; as mais numerosas foram $P$. gonoacantha, C. floribundus, B. forficata, Mollinedia widgrenii e Rollinia dolabripetala; as mais freqüentes foram $M$. widgrenii, Jacaranda macrantha, $R$. dolabripetala, $P$. gonoacantha e B. forficata. No Interior, exibiram maiores áreas basais Cariniana legalis, Coussapoa microcarpa, Metrodorea stipularis, Esenbeckia leiocarpa e Virola bicuhyba; apresentaram maiores densidades Galipea jasminiflora, M. stipularis, Anaxagorea silvatica, $V$. bicuhyba e Prunus myrtifolia; e foram mais freqüentes $M$. stipularis, A. silvatica, $V$. bicuhyba, Rollinia sylvatica e J. macrantha.
Foram registrados 1778 indivíduos com DAP $\geq 5$ $\mathrm{cm}$, somando uma área basal de $50,73 \mathrm{~m}^{2}$. Dentre os parâmetros estruturais comparados, somente área basal não diferiu estatisticamente entre borda e interior do fragmento (tabela 2). A densidade foi significativamente maior na borda, enquanto os maiores diâmetros e alturas ocorreram no interior. As distribuições de densidade por classes de diâmetro e altura (figura 2) mostram valores estatisticamente superiores na borda para as menores classes de tamanho, com diferenças pronunciadas nas classes de 0 a $10 \mathrm{~m}$ de altura e de 5 a $33 \mathrm{~cm}$ de diâmetro. O índice de Shannon $\left(H^{\prime}\right)$ da amostra total foi de 4,415 nats indivíduo ${ }^{-1}$ e a equabilidade de Pielou $(J ')$ foi de 0,855 . Foram encontradas diferenças significativas entre Borda e Interior, tanto para $H^{\prime}$ como para a densidade de espécies por parcelas, ambos mais elevados na Borda (tabela 3), que também exibiu maior $J$, ou seja, menor dominância ecológica, e maiores projeções da riqueza de espécies pelos estimadores "jack-knife". Observe-se, porém, que estes estimadores foram ambos superados pelo levantamento florístico.

Os subgrupos de solos encontrados foram Latossolos Vermelho-Amarelos Ácricos típicos, Argissolos Vermelho-Amarelos Distróficos típicos e Argissolos Vermelho-Amarelos Eutróficos típicos, doravante referidos apenas como Latossolo, Argissolo D e Argissolo E. A distribuição dos solos no fragmento encontra-se na figura 3. As variáveis topográficas e edáficas das parcelas correspondentes aos três subgrupos de solo são fornecidas na tabela 4. A cota média foi significativamente mais elevada no Latossolo, que é acentuadamente drenado e concentrado no alto da encosta. Os bem drenados Argissolos se distribuem na encosta. O desnível do terreno não diferiu significativamente entre os solos. $\mathrm{O} \mathrm{pH}$ e os teores de $\mathrm{Ke} \mathrm{Ca}$ foram significativamente mais altos no Argissolo $\mathrm{E}$, enquanto $\mathrm{Mg}$ foi mais baixo no Argissolo D. Os teores de Al diminuíram significativamente do Latossolo para o Argissolo D e deste para o Argissolo E, enquanto a saturação por bases aumentou no sentido oposto. A matéria orgânica diferiu entre os extremos, mais alta nos Latossolos e mais baixa nos Argissolos D. Os Argissolos apresentaram mais areia e menos argila que o Latossolo e o silte foi mais elevado no Argissolo E. Em síntese, a microbacia apresenta um gradiente edáfico caracterizado por status nutricional com riqueza crescente do Latossolo para o Argissolo D e deste para Argissolo E, enquanto a textura evoluiu, no mesmo sentido, de maiores concentrações de argila e menores de areia (Latossolo) para concentrações crescentes de areia (Argissolos) e silte (Argissolo E). 
Tabela 1. Espécies arbóreas do fragmento de floresta semidecídua inventariado em Piedade do Rio Grande, MG. Parâmetros quantitativos das árvores individuais registradas nas parcelas de Interior e Borda. $\mathrm{N}=$ número de indivíduos, $\mathrm{P}=$ número de parcelas com ocorrência da espécie, $\mathrm{AB}=$ área basal $\left(\mathrm{m}^{2}\right)$. $\mathrm{Nr}=$ número de registro no Herbário ESAL.

Table 1. Tree species of the fragment of tropical semideciduous forest surveyed in Piedade do Rio Grande, SE Brazil. Quantitative parameters of individual trees registered in the Interior and Edge plots: $\mathrm{N}=$ number of individuals, $\mathrm{P}=$ number of plots where the species occurred, $\mathrm{AB}=$ basal area $\left(\mathrm{m}^{2}\right) . \mathrm{Nr}=$ registration number $(\mathrm{Nr})$ at the ESAL Herbarium.

\begin{tabular}{|c|c|c|c|c|c|c|c|}
\hline \multirow[t]{2}{*}{ Famílias e espécies } & \multirow[b]{2}{*}{$\mathrm{Nr}$} & \multicolumn{3}{|c|}{ Interior $(n=18)$} & \multicolumn{3}{|c|}{$\operatorname{Borda}(n=12)$} \\
\hline & & $\mathrm{N}$ & $\mathrm{P}$ & $\mathrm{AB}$ & $\mathrm{N}$ & $\mathrm{P}$ & $\mathrm{AB}$ \\
\hline \multicolumn{8}{|l|}{ ANACARDIACEAE } \\
\hline Astronium graveolens Jacq.* & 17969 & - & - & - & - & - & - \\
\hline Lithraea molleoides (Vell.) Engl. & 17434 & - & - & - & 7 & 4 & 0,086 \\
\hline Schinus terebinthifolius Raddi & 17056 & - & - & - & 3 & 2 & 0,007 \\
\hline Tapirira guianensis Aublet & 17435 & - & - & - & 1 & 1 & 0,002 \\
\hline Tapirira obtusa (Benth.) J.D.Mitch. & 17057 & 4 & 2 & 0,191 & 17 & 5 & 0,156 \\
\hline \multicolumn{8}{|l|}{ ANNONACEAE } \\
\hline Anaxagorea silvatica R.E.Fr. & 17060 & 48 & 14 & 0,716 & - & - & - \\
\hline Annona cacans Warm. & 17058 & 2 & 2 & 0,160 & 1 & 1 & 0,080 \\
\hline Duguetia lanceolata A.St.-Hil.* & 14936 & - & - & - & - & - & - \\
\hline Guatteria australis A.St.-Hil. & 17061 & - & - & - & 3 & 3 & 0,047 \\
\hline Rollinia dolabripetala (Raddi) R.E.Fr. & 16221 & 16 & 11 & 0,318 & 32 & 10 & 0,277 \\
\hline Rollinia laurifolia Schltdl. & 17062 & 13 & 8 & 0,252 & 25 & 8 & 0,425 \\
\hline Rollinia sylvatica (A.St.-Hil.) Mart. & 17442 & 15 & 11 & 0,105 & 1 & 1 & 0,021 \\
\hline Xylopia brasiliensis Spreng. & 17063 & 3 & 3 & 0,120 & 2 & 1 & 0,010 \\
\hline \multicolumn{8}{|l|}{ APOCYNACEAE } \\
\hline Aspidosperma australe Müll.Arg. & 17065 & 8 & 6 & 0,246 & - & - & - \\
\hline Aspidosperma cylindrocarpon Müll.Arg.* & 17064 & - & - & - & - & - & - \\
\hline Aspidosperma polyneuron Müll.Arg. & 16377 & 5 & 4 & 0,555 & 1 & 1 & 0,179 \\
\hline Aspidosperma ramiflorum Müll.Arg.* & 17066 & - & - & - & - & - & - \\
\hline Aspidosperma spruceanum Benth. ex Müll.Arg. & 17976 & - & - & - & 1 & 1 & 0,022 \\
\hline \multicolumn{8}{|l|}{ AQUIFOLIACEAE } \\
\hline Ilex cerasifolia Reissek & 17067 & 1 & 1 & 0,003 & 1 & 1 & 0,004 \\
\hline \multicolumn{8}{|l|}{ ARALIACEAE } \\
\hline Dendropanax cuneatus (DC.) Decne. \& Planch. & 18003 & - & - & - & 1 & 1 & 0,003 \\
\hline Schefflera calva (Cham.) Frodin \& Fiaschi & 17646 & 3 & 3 & 0,095 & - & - & - \\
\hline \multicolumn{8}{|l|}{ ARAUCARIACEAE } \\
\hline Araucaria angustifolia (Bert.) Kuntze & 17068 & - & - & - & 2 & 1 & 0,700 \\
\hline \multicolumn{8}{|l|}{ ARECACEAE } \\
\hline Geonoma schottiana Mart. & 16385 & 4 & 2 & 0,010 & 3 & 2 & 0,007 \\
\hline Syagrus romanzoffiana (Cham.) Glassman & 16903 & - & - & - & 4 & 2 & 0,032 \\
\hline \multicolumn{8}{|l|}{ ASTERACEAE } \\
\hline Austrocritonia angulicaulis (Sch.Bip.) R.M.King \& H.Rob. & & - & - & - & - & - & - \\
\hline Austroeupatorium inulifolium (Kunth) R.M.King \& H.Rob. & 17069 & - & - & - & 5 & 2 & 0,092 \\
\hline Gochnatia paniculata (Less.) Cabrera* & 17070 & - & - & - & - & - & - \\
\hline Piptocarpha axillaris (Less.) Baker & 17088 & - & - & - & 7 & 3 & 0,142 \\
\hline Piptocarpha macropoda Baker & 17071 & 1 & 1 & 0,089 & - & - & - \\
\hline Vernonanthura divaricata (Spreng.) H.Rob. & 17072 & 1 & 1 & 0,079 & 3 & 3 & 0,024 \\
\hline Vernonanthura discolor (Spreng.) H.Rob.* & 17250 & - & - & - & - & - & - \\
\hline Vernonanthura phosphorica (Vell.) H.Rob.* & 17073 & - & - & - & - & - & - \\
\hline
\end{tabular}


continuação

\begin{tabular}{|c|c|c|c|c|c|c|c|}
\hline \multirow[t]{2}{*}{ Famílias e espécies } & \multirow[b]{2}{*}{$\mathrm{Nr}$} & \multicolumn{3}{|c|}{ Interior $(n=18)$} & \multicolumn{3}{|c|}{ Borda $(n=12)$} \\
\hline & & $\mathrm{N}$ & $\mathrm{P}$ & $\mathrm{AB}$ & $\mathrm{N}$ & $\mathrm{P}$ & $\mathrm{AB}$ \\
\hline \multicolumn{8}{|l|}{ BIGNONIACEAE } \\
\hline Jacaranda macrantha Cham. & 17074 & 24 & 10 & 0,728 & 21 & 10 & 0,461 \\
\hline Jacaranda subalpina W.Morawetz* & 16233 & - & - & - & - & - & - \\
\hline Tabebuia chrysotricha (Mart.) Standl.* & 16751 & - & - & - & - & - & - \\
\hline Tabebuia serratifolia (Vahl) Nichols* & 17075 & - & - & - & - & - & - \\
\hline Zeyheria tuberculosa (Vell.) Bureau* & 14854 & - & - & - & - & - & - \\
\hline \multicolumn{8}{|l|}{ BORAGINACEAE } \\
\hline Cordia ecalyculata Vell.* & 17078 & - & - & - & - & - & - \\
\hline Cordia sellowiana Cham. & 17079 & 4 & 3 & 0,114 & 6 & 3 & 0,206 \\
\hline Cordia superba Cham. & 14618 & - & - & - & 6 & 1 & 0,082 \\
\hline \multicolumn{8}{|l|}{ BURSERACEAE } \\
\hline Protium spruceanum (Benth.) Engl.* & 16759 & - & - & - & - & - & - \\
\hline Protium widgrenii Engl. & 17080 & 1 & 1 & 0,002 & 25 & 5 & 0,381 \\
\hline \multicolumn{8}{|l|}{ CANELLACEAE } \\
\hline Capsicodendron dinisii (Schwacke) Occhioni & 17081 & 1 & 1 & 0,030 & 2 & 1 & 0,038 \\
\hline \multicolumn{8}{|l|}{ CANNABACEAE } \\
\hline Celtis iguanaea (Jacq.) Sarg. & 16940 & 1 & 1 & 0,014 & - & - & - \\
\hline Trema micrantha $(\mathrm{L}$.$) Blume$ & 17223 & 1 & 1 & 0,016 & 1 & 1 & 0,019 \\
\hline \multicolumn{8}{|l|}{ CARDIOPTERIDACEAE } \\
\hline Citronella paniculata (Mart.) R.A.Howard & 17110 & - & - & - & 1 & 1 & 0,005 \\
\hline \multicolumn{8}{|l|}{ CELASTRACEAE } \\
\hline Maytenus aquifolia Mart. & 17084 & - & - & - & 5 & 2 & 0,038 \\
\hline Maytenus glazioviana Loes. & 17452 & - & - & - & 1 & 1 & 0,003 \\
\hline Maytenus salicifolia Reissek* & 17085 & - & - & - & - & - & - \\
\hline Plenckia populnea Reissek* & 17083 & - & - & - & - & - & - \\
\hline \multicolumn{8}{|l|}{ CLETHRACEAE } \\
\hline Clethra scabra Pers. & 17086 & - & - & - & 16 & 4 & 0,238 \\
\hline \multicolumn{8}{|l|}{ CLUSIACEAE } \\
\hline Calophyllum brasiliense Cambess.* & 12698 & - & - & - & - & - & - \\
\hline Chrysochlamys saldanhae (Engl.) Oliveira-Filho & 17087 & 2 & 2 & 0,249 & - & - & - \\
\hline \multicolumn{8}{|l|}{ COMBRETACEAE } \\
\hline Terminalia glabrescens Mart.* & 16410 & - & - & - & - & - & - \\
\hline \multicolumn{8}{|l|}{ CONNARACEAE } \\
\hline Connarus regnellii G.Schellenb. & 17088 & 6 & 6 & 0,414 & 1 & 1 & 0,004 \\
\hline \multicolumn{8}{|l|}{ CUNONIACEAE } \\
\hline Lamanonia ternata Vell. & 17090 & - & - & - & 8 & 5 & 0,420 \\
\hline \multicolumn{8}{|l|}{ CYATHEACEAE } \\
\hline Cyathea phalerata Mart.* & 17263 & - & - & - & - & - & - \\
\hline \multicolumn{8}{|l|}{ EBENACEAE } \\
\hline Diospyros hispida A.DC.* & 12654 & - & - & - & - & - & - \\
\hline \multicolumn{8}{|l|}{ ELAEOCARPACEAE } \\
\hline Sloanea guianensis (Aublet) Benth.* & 17266 & - & - & - & - & - & - \\
\hline Sloanea monosperma Vell. & 17091 & 1 & 1 & 0,004 & - & - & - \\
\hline \multicolumn{8}{|l|}{ ERYTHROXYLACEAE } \\
\hline Erythroxylum cuneifolium (Mart.) O.E.Schulz & 17092 & - & - & - & 1 & 1 & 0,002 \\
\hline Erythroxylum cuspidifolium Mart. & 17093 & 1 & 1 & 0,015 & - & - & - \\
\hline Erythroxylum deciduum A.St.-Hil.* & 17094 & - & - & - & - & - & - \\
\hline
\end{tabular}


continuação

\begin{tabular}{|c|c|c|c|c|c|c|c|}
\hline \multirow[t]{2}{*}{ Famílias e espécies } & \multirow[b]{2}{*}{$\mathrm{Nr}$} & \multicolumn{3}{|c|}{ Interior $(n=18)$} & \multicolumn{3}{|c|}{$\operatorname{Borda}(n=12)$} \\
\hline & & $\mathrm{N}$ & $\mathrm{P}$ & $\mathrm{AB}$ & $\mathrm{N}$ & $\mathrm{P}$ & $\mathrm{AB}$ \\
\hline \multicolumn{8}{|l|}{ EUPHORBIACEAE } \\
\hline Alchornea glandulosa Poepp. \& Endl. & 17096 & 2 & 2 & 0,011 & 1 & 1 & 0,014 \\
\hline Alchornea sidifolia Müll.Arg.* & 17268 & - & - & - & - & - & - \\
\hline Alchornea triplinervia (Spreng.) Müll.Arg. & 17097 & 4 & 4 & 0,190 & - & - & - \\
\hline Croton floribundus Spreng. & 17099 & 5 & 2 & 0,197 & 50 & 6 & 0,884 \\
\hline Croton urucurana Baill.* & 12357 & - & - & - & - & - & - \\
\hline Croton verrucosus Radcl.-Sm. \& Govaerts & 17098 & 10 & 7 & 0,394 & 23 & 5 & 0,636 \\
\hline Manihot grahamii Hook. & 17102 & - & - & - & 1 & 1 & 0,003 \\
\hline Pera glabrata (Schott) Poepp. ex Baill. & 17104 & 2 & 2 & 0,044 & 2 & 2 & 0,088 \\
\hline Sapium glandulosum (L.) Morong* & 16787 & - & - & - & - & - & - \\
\hline Sebastiania commersoniana (Baill.) L.B.Sm. \& Downs & 17095 & 5 & 2 & 0,032 & - & - & - \\
\hline \multicolumn{8}{|l|}{ FABACEAE CAESALPINIOIDEAE } \\
\hline Bauhinia forficata Link & 17125 & 5 & 5 & 0,216 & 50 & 8 & 0,756 \\
\hline Cassia ferruginea (Schrad.) Schrad. ex DC. & 17126 & 1 & 1 & 0,093 & 2 & 2 & 0,117 \\
\hline Copaifera langsdorffii Desf. & 17475 & 2 & 2 & 0,010 & 3 & 2 & 0,234 \\
\hline Hymenaea courbaril L.* & 18023 & - & - & - & - & - & - \\
\hline Senna macranthera (Collad.) H.S.Irwin \& Barneby & 17476 & - & - & - & 2 & 2 & 0,013 \\
\hline Tachigali rugosa (Mart. ex Benth.) Zarucchi \& Pipoly* & 16819 & - & - & - & - & - & - \\
\hline \multicolumn{8}{|l|}{ FABACEAEFABOIDEAE } \\
\hline Dalbergia brasiliensis Vogel* & 15036 & - & - & - & - & - & - \\
\hline Dalbergia villosa (Benth.) Benth.* & 17129 & - & - & - & - & - & - \\
\hline Lonchocarpus muehlbergianus Hassl.* & 18028 & - & - & - & - & - & - \\
\hline Machaerium brasiliense Vogel & 17130 & 1 & 1 & 0,044 & - & - & - \\
\hline Machaerium hirtum (Vell.) Stellfeld & 16517 & - & - & - & 1 & 1 & 0,002 \\
\hline Machaerium nictitans (Vell.) Benth. & 17127 & 7 & 6 & 0,632 & 12 & 7 & 0,143 \\
\hline Machaerium stipitatum (DC.) Vogel & 17131 & 1 & 1 & 0,013 & 3 & 2 & 0,014 \\
\hline Machaerium villosum Vogel & 17484 & 1 & 1 & 0,079 & 18 & 4 & 1,449 \\
\hline Myroxylon peruiferum L.f.* & 17128 & - & - & - & - & - & - \\
\hline Ormosia arborea (Vell.) Harms* & 18034 & - & - & - & - & - & - \\
\hline Platycyamus regnellii Benth. & 16843 & 9 & 6 & 0,474 & 1 & 1 & 0,010 \\
\hline Platypodium elegans Vogel* & 17132 & - & - & - & - & - & - \\
\hline \multicolumn{8}{|l|}{ FABACEAE MIMOSOIDEAE } \\
\hline Acacia polyphylla $\mathrm{DC}$. & 17133 & 2 & 2 & 0,013 & 3 & 1 & 0,061 \\
\hline Albizia polycephala (Benth.) Killip ex Record & 17134 & 3 & 3 & 0,084 & 3 & 1 & 0,057 \\
\hline Anadenanthera colubrina (Vell.) Brenan & 17935 & - & - & - & 2 & 1 & 0,006 \\
\hline Inga ingoides (Rich.) Willd. & 17489 & 1 & 1 & 0,010 & 1 & 1 & 0,020 \\
\hline Inga marginata Willd. & 17136 & 6 & 5 & 0,069 & 2 & 2 & 0,015 \\
\hline Inga striata Benth. & 17137 & 1 & 1 & 0,008 & 1 & 1 & 0,006 \\
\hline Leucochloron incuriale (Vell.) Barneby \& J.W.Grimes & 18042 & - & - & - & 8 & 2 & 0,201 \\
\hline Piptadenia gonoacantha (Mart.) J.F.Macbr. & 17135 & 7 & 5 & 0,867 & 67 & 8 & 2,555 \\
\hline \multicolumn{8}{|l|}{ HYPERICACEAE } \\
\hline Vismia brasiliensis Choisy & 17652 & - & - & - & 6 & 3 & 0,044 \\
\hline \multicolumn{8}{|l|}{ LACISTEMATACEAE } \\
\hline Lacistema hasslerianum Chodat* & 12644 & - & - & - & - & - & - \\
\hline \multicolumn{8}{|l|}{ LAMIACEAE } \\
\hline Aegiphila sellowiana Cham. & 17192 & 1 & 1 & 0,007 & 7 & 2 & 0,113 \\
\hline Hyptidendron asperrimum (Epling) Harley & 17111 & - & - & - & 19 & 5 & 0,426 \\
\hline Vitex polygama Cham. & 17193 & - & - & - & 2 & 2 & 0,007 \\
\hline Vitex sellowiana Cham. & 17773 & - & - & - & 1 & 1 & 0,003 \\
\hline
\end{tabular}


continuação

\begin{tabular}{|c|c|c|c|c|c|c|c|}
\hline \multirow[t]{2}{*}{ Famílias e espécies } & \multirow[b]{2}{*}{$\mathrm{Nr}$} & \multicolumn{3}{|c|}{ Interior $(n=18)$} & \multicolumn{3}{|c|}{ Borda $(n=12)$} \\
\hline & & $\mathrm{N}$ & $\mathrm{P}$ & $\mathrm{AB}$ & $\mathrm{N}$ & $\mathrm{P}$ & $\mathrm{AB}$ \\
\hline \multicolumn{8}{|l|}{ LAURACEAE } \\
\hline Cinnamoтит triplinerve (Ruiz \& Pav.) Kosterm. & 17112 & 1 & 1 & 0,168 & 1 & 1 & 0,005 \\
\hline Cryptocarya aschersoniana $\mathrm{Mez}$ & 17113 & 11 & 4 & 0,496 & 4 & 3 & 0,275 \\
\hline Endlicheria paniculata (Spreng.) J.F.Macbr.* & 17114 & - & - & - & - & - & - \\
\hline Nectandra grandiflora Nees & 17115 & - & - & - & 4 & 2 & 0,381 \\
\hline Nectandra lanceolata Nees & 16248 & - & - & - & 2 & 1 & 0,005 \\
\hline Nectandra megapotamica (Spreng.) Mez & 17116 & 6 & 3 & 0,117 & - & - & - \\
\hline Nectandra nitidula Nees & 16809 & 1 & 1 & 0,064 & 4 & 4 & 0,187 \\
\hline Nectandra oppositifolia Nees* & 17466 & - & - & - & - & - & - \\
\hline Ocotea aciphylla (Nees) Mez* & 17467 & - & - & - & - & - & - \\
\hline Ocotea brachybotra (Meisn.) Mez* & 17468 & - & - & - & - & - & - \\
\hline Ocotea corymbosa (Meisn.) Mez & 17117 & 9 & 4 & 0,066 & 7 & 6 & 0,031 \\
\hline Ocotea diospyrifolia (Meisn.) Mez* & 17118 & - & - & - & - & - & - \\
\hline Ocotea elegans Mez & 17119 & 3 & 3 & 0,020 & 1 & 1 & 0,007 \\
\hline Ocotea laxa (Nees) Mez* & 18017 & - & - & - & - & - & - \\
\hline Ocotea longifolia Kunth & 17120 & 3 & 1 & 0,043 & - & - & - \\
\hline Ocotea odorifera (Vell.) Rohwer & 17121 & 11 & 7 & 0,301 & 10 & 4 & 0,063 \\
\hline Ocotea puberula (Rich.) Nees & 16632 & 1 & 1 & 0,018 & 2 & 1 & 0,012 \\
\hline Ocotea pulchella Mart.* & 16810 & - & - & - & - & - & - \\
\hline Ocotea silvestris Vattimo-Gil & 17730 & - & - & - & 5 & 4 & 0,089 \\
\hline Persea fulva L.E.Kopp* & 16497 & - & - & - & - & - & - \\
\hline Persea major (Nees) L.E.Kopp & 17122 & - & - & - & 9 & 5 & 0,351 \\
\hline \multicolumn{8}{|l|}{ LECYTHIDACEAE } \\
\hline Cariniana estrellensis (Raddi) Kuntze & 17123 & 3 & 3 & 0,734 & 3 & 2 & 0,034 \\
\hline Cariniana legalis (Mart.) Kuntze & 17124 & 3 & 2 & 3,705 & - & - & - \\
\hline \multicolumn{8}{|l|}{ LOGANIACEAE } \\
\hline Strychnos brasiliensis (Spreng.) Mart. & 17138 & - & - & - & 2 & 2 & 0,005 \\
\hline \multicolumn{8}{|l|}{ LYTHRACEAE } \\
\hline Lafoensia pacari A.St.-Hil.* & 11896 & - & - & - & - & - & - \\
\hline \multicolumn{8}{|l|}{ MAGNOLIACEAE } \\
\hline Magnolia ovata (A.St.-Hil.) Spreng. & 17139 & 3 & 1 & 0,088 & - & - & - \\
\hline \multicolumn{8}{|l|}{ MALPIGHIACEAE } \\
\hline Byrsonima laxiflora Griseb. & 12497 & 1 & 1 & 0,029 & - & - & - \\
\hline \multicolumn{8}{|l|}{ MALVACEAE } \\
\hline Ceiba speciosa (A.St.-Hil.) Ravenna & 17076 & 7 & 7 & 1,120 & 1 & 1 & 0,039 \\
\hline Eriotheca candolleana (K.Schum.) A.Robyns* & 16999 & - & - & - & - & - & - \\
\hline Luehea candicans Mart. \& Zucc.* & 17222 & - & - & - & - & - & - \\
\hline Luehea divaricata Mart. & 17720 & - & - & - & 11 & 3 & 0,253 \\
\hline Luehea grandiflora Mart. \& Zucc.* & 16855 & - & - & - & - & - & - \\
\hline Pseudobombax grandiflorum (Cav.) A.Robyns & 17077 & 10 & 7 & 0,865 & 2 & 2 & 0,065 \\
\hline \multicolumn{8}{|l|}{ MELASTOMATACEAE } \\
\hline Leandra aurea (Cham.) Cogn.* & 17140 & - & - & - & - & - & - \\
\hline Leandra scabra DC.*' & 17141 & - & - & - & - & - & - \\
\hline Miconia albicans Triana* & 10895 & - & - & - & - & - & - \\
\hline Miconia argyrophylla DC. & 17142 & 3 & 3 & 0,060 & 2 & 2 & 0,017 \\
\hline Miconia cinnamomifolia (DC.) Naudin* & 17143 & - & - & - & - & - & - \\
\hline Miconia corallina Spring* & 15436 & - & - & - & - & - & - \\
\hline Miconia latecrenata (DC.) Naudin & 17144 & - & - & - & 2 & 2 & 0,006 \\
\hline Miconia ligustroides (DC.) Naudin* & 17145 & - & - & - & - & - & - \\
\hline
\end{tabular}


continuação

\begin{tabular}{|c|c|c|c|c|c|c|c|}
\hline \multirow[t]{2}{*}{ Famílias e espécies } & \multirow[b]{2}{*}{$\mathrm{Nr}$} & \multicolumn{3}{|c|}{ Interior $(n=18)$} & \multicolumn{3}{|c|}{ Borda $(n=12)$} \\
\hline & & $\mathrm{N}$ & $\mathrm{P}$ & $\mathrm{AB}$ & $\mathrm{N}$ & $\mathrm{P}$ & $\mathrm{AB}$ \\
\hline Miconia pepericarpa DC.* & 17146 & - & - & - & - & - & - \\
\hline Miconia prasina (Sw.) DC.* & 17307 & - & - & - & - & - & - \\
\hline Miconia sellowiana Naudin* & 17312 & - & - & - & - & - & - \\
\hline Miconia trianaei Cogn.* & 17147 & - & - & - & - & - & - \\
\hline Tibouchina estrellensis (Raddi) Cogn.* & 15099 & - & - & - & - & - & - \\
\hline Tibouchina sellowiana (Cham.) Cogn.* & 16258 & - & - & - & - & - & - \\
\hline Tibouchina stenocarpa (DC.) Cogn.* & 16859 & - & - & - & - & - & - \\
\hline \multicolumn{8}{|l|}{ MELIACEAE } \\
\hline Cabralea canjerana (Vell.) Mart. & 12487 & 13 & 5 & 1,434 & 17 & 8 & 0,383 \\
\hline Cedrela fissilis Vell. & 12234 & - & - & - & 5 & 3 & 0,126 \\
\hline Guarea kunthiana A.Juss. & 17149 & 2 & 2 & 0,025 & 1 & 1 & 0,004 \\
\hline Guarea macrophylla Vahl* & 17728 & - & - & - & - & - & - \\
\hline Trichilia catigua A.Juss. & 17150 & 15 & 4 & 0,114 & - & - & - \\
\hline Trichilia clausseni C.DC. & 17151 & - & - & - & 2 & 1 & 0,025 \\
\hline Trichilia elegans A.Juss. & 17154 & 2 & 2 & 0,042 & - & - & - \\
\hline Trichilia emarginata (Turcz.) C.DC. & 17152 & 3 & 2 & 0,036 & 2 & 2 & 0,005 \\
\hline Trichilia lepidota Mart. & 17153 & 6 & 5 & 0,038 & - & - & - \\
\hline Trichilia pallida $\mathrm{Sw}$. & 12478 & 3 & 2 & 0,007 & - & - & - \\
\hline \multicolumn{8}{|l|}{ MONIMIACEAE } \\
\hline Mollinedia argyrogyna Perkins & 15703 & - & - & - & 1 & 1 & 0,005 \\
\hline Mollinedia clavigera Tul.* & 15428 & - & - & - & - & - & - \\
\hline Mollinedia widgrenii A.DC. & 17155 & 18 & 8 & 0,194 & 33 & 12 & 0,226 \\
\hline \multicolumn{8}{|l|}{ MORACEAE } \\
\hline Ficus adhatodifolia Schott* & 17159 & - & - & - & - & - & - \\
\hline Ficus calyptroceras (Miq.) Miq.* & 17162 & - & - & - & - & - & - \\
\hline Ficus enormis (Mart.) Miq. & 17161 & - & - & - & 2 & 2 & 0,121 \\
\hline Ficus gomelleira Kunth \& Bouché* & 17158 & - & - & - & - & - & - \\
\hline Ficus luschnathiana (Miq.) Miq.* & 17160 & - & - & - & - & - & - \\
\hline Maclura tinctoria (L.) Steud. & 17163 & - & - & - & 1 & 1 & 0,003 \\
\hline Sorocea bonplandii (Baill.) W.Burger & 17164 & 1 & 1 & 0,011 & 3 & 1 & 0,007 \\
\hline \multicolumn{8}{|l|}{ MYRISTICACEAE } \\
\hline Virola bicuhyba (Schott) Warb. & 17165 & 29 & 13 & 1,648 & 2 & 1 & 0,004 \\
\hline \multicolumn{8}{|l|}{ MYRSINACEAE } \\
\hline Cybianthus cuneifolius Mart.* & 17166 & - & - & - & - & - & - \\
\hline Myrsine gardneriana A.DC. & 17030 & - & - & - & 1 & 1 & 0,003 \\
\hline Myrsine umbellata Mart. & 17167 & - & - & - & 23 & 6 & 0,090 \\
\hline \multicolumn{8}{|l|}{ MYRTACEAE } \\
\hline Blepharocalyx salicifolius (Kunth) O.Berg* & 17325 & - & - & - & - & - & - \\
\hline Calyptranthes clusiifolia O.Berg & 17168 & 3 & 3 & 0,019 & 16 & 4 & 0,140 \\
\hline Calyptranthes concinna DC.* & 16264 & - & - & - & - & - & - \\
\hline Calyptranthes widgreniana O.Berg & 16265 & 1 & 1 & 0,005 & - & - & - \\
\hline Campomanesia guaviroba (DC.) Kiaersk.* & 17170 & - & - & - & - & - & - \\
\hline Campomanesia guazumifolia (Cambess.) O.Berg & 17169 & 1 & 1 & 0,014 & 1 & 1 & 0,002 \\
\hline Eugenia acutata Miq. & 17032 & 1 & 1 & 0,015 & - & - & - \\
\hline Eugenia dodonaeifolia Cambess. & 17179 & 1 & 1 & 0,004 & - & - & - \\
\hline Eugenia florida DC.* & 15090 & - & - & - & - & - & - \\
\hline Eugenia hiemalis Cambess. & 12246 & - & - & - & 1 & 1 & 0,007 \\
\hline Eugenia involucrata DC. & 17172 & 3 & 3 & 0,065 & 1 & 1 & 0,003 \\
\hline
\end{tabular}


continuação

\begin{tabular}{|c|c|c|c|c|c|c|c|}
\hline \multirow[t]{2}{*}{ Famílias e espécies } & \multirow[b]{2}{*}{$\mathrm{Nr}$} & \multicolumn{3}{|c|}{ Interior $(n=18)$} & \multicolumn{3}{|c|}{$\operatorname{Borda}(n=12)$} \\
\hline & & $\mathrm{N}$ & $\mathrm{P}$ & $\mathrm{AB}$ & $\mathrm{N}$ & $\mathrm{P}$ & $\mathrm{AB}$ \\
\hline Eugenia klotzschiana O.Berg* & 15540 & - & - & - & - & - & - \\
\hline Eugenia leptoclada O.Berg* & 17171 & - & - & - & - & - & - \\
\hline Marlierea excoriata Mart. & 17175 & 6 & 5 & 0,020 & - & - & - \\
\hline Marlierea racemosa (Vell.) Kiaersk. & 17174 & 6 & 2 & 0,047 & 7 & 4 & 0,042 \\
\hline Myrcia cordiifolia DC.* & 17173 & - & - & - & - & - & - \\
\hline Myrcia splendens (Sw.) DC. & 17779 & 2 & 2 & 0,008 & 24 & 7 & 0,267 \\
\hline Myrcia tomentosa (Aublet) DC. & 12266 & - & - & - & 3 & 3 & 0,008 \\
\hline Myrciaria floribunda (H.West ex Willd.) O.Berg* & 16279 & - & - & - & - & - & - \\
\hline Myrciaria tenella (DC.) O.Berg* & 16894 & - & - & - & - & - & - \\
\hline Plinia cauliflora (Mart.) Kausel & 17178 & 1 & 1 & 0,003 & - & - & - \\
\hline \multicolumn{8}{|l|}{ NYCTAGINACEAE } \\
\hline Guapira opposita (Vell.) Reitz & 17180 & 17 & 8 & 0,227 & 3 & 2 & 0,008 \\
\hline Pisonia zapallo Griseb. & 17181 & 5 & 4 & 0,172 & 3 & 3 & 0,013 \\
\hline \multicolumn{8}{|l|}{ OLACACEAE } \\
\hline Heisteria silvianii Schwacke* & 17182 & - & - & - & - & - & - \\
\hline \multicolumn{8}{|l|}{ PHYLLANTHACEAE } \\
\hline Hieronyma alchorneoides Allemão & 17101 & 4 & 3 & 0,100 & 6 & 2 & 0,325 \\
\hline Savia dictyocarpa Müll.Arg. & 17103 & 2 & 2 & 0,052 & - & - & - \\
\hline \multicolumn{8}{|l|}{ PHYTOLACCACEAE } \\
\hline Seguieria langsdorffii Moq. & 17184 & 2 & 1 & 0,017 & 7 & 2 & 0,115 \\
\hline \multicolumn{8}{|l|}{ PICRAMNIACEAE } \\
\hline Picramnia glazioviana Engl. & 17214 & 2 & 2 & 0,005 & - & - & - \\
\hline \multicolumn{8}{|l|}{ PIPERACEAE } \\
\hline Piper aduncum L. & 17185 & - & - & - & 1 & 1 & 0,009 \\
\hline Piper amalago L.* & 17041 & - & - & - & - & - & - \\
\hline Piper caldense C.DC.* & 17186 & - & - & - & - & - & - \\
\hline \multicolumn{8}{|l|}{ PROTEACEAE } \\
\hline Euplassa legalis (Vell.) I.M.Johnst. & 15127 & - & - & - & 1 & 1 & 0,014 \\
\hline Euplassa organensis (Gardn.) I.M.Johnst.* & 17348 & - & - & - & - & - & - \\
\hline Roupala montana Aubl.* & 17190 & - & - & - & - & - & - \\
\hline Roupala rhombifolia Mart.* & 16289 & - & - & - & - & - & - \\
\hline \multicolumn{8}{|l|}{ RHAMNACEAE } \\
\hline Colubrina glandulosa Perkins & 16141 & 8 & 4 & 0,272 & 11 & 3 & 0,078 \\
\hline \multicolumn{8}{|l|}{ ROSACEAE } \\
\hline Prunus myrtifolia (L.) Urb. & 17194 & 27 & 9 & 0,808 & 2 & 1 & 0,007 \\
\hline \multicolumn{8}{|l|}{ RUBIACEAE } \\
\hline Alseis floribunda Schott & 17196 & 2 & 1 & 0,009 & - & - & - \\
\hline Amaioua guianensis Aublet & 17197 & 5 & 4 & 0,063 & 2 & 1 & 0,020 \\
\hline Chomelia sericea Müll.Arg.* & 13722 & - & - & - & - & - & - \\
\hline Cordiera sessilis (Vell.) Kuntze & 17195 & - & - & - & 3 & 3 & 0,044 \\
\hline Guettarda viburnoides Cham. \& Schltdl. & 17199 & - & - & - & 2 & 2 & 0,008 \\
\hline Ixora brevifolia Benth. & 17200 & 6 & 2 & 0,048 & 11 & 3 & 0,191 \\
\hline Posoqueria latifolia (Rudge) Roem. \& Schult.* & 13227 & - & - & - & - & - & - \\
\hline Psychotria vellosiana Benth. & 17201 & 1 & 1 & 0,002 & 3 & 2 & 0,019 \\
\hline Randia armata (Sw.) DC.* & 17202 & - & - & - & - & - & - \\
\hline Rudgea jasminoides (Cham.) Müll.Arg. & 17203 & 3 & 2 & 0,008 & - & - & - \\
\hline \multicolumn{8}{|l|}{ RUTACEAE } \\
\hline Esenbeckia leiocarpa Engl. & 17204 & 6 & 5 & 2,001 & - & - & - \\
\hline
\end{tabular}


continuação

\begin{tabular}{|c|c|c|c|c|c|c|c|}
\hline \multirow[t]{2}{*}{ Famílias e espécies } & \multirow[b]{2}{*}{$\mathrm{Nr}$} & \multicolumn{3}{|c|}{ Interior $(n=18)$} & \multicolumn{3}{|c|}{$\operatorname{Borda}(n=12)$} \\
\hline & & $\mathrm{N}$ & $\mathrm{P}$ & $\mathrm{AB}$ & $\mathrm{N}$ & $\mathrm{P}$ & $\mathrm{AB}$ \\
\hline Galipea jasminiflora (A.St.-Hil.) Engl. & 17205 & 103 & 9 & 0,916 & 22 & 5 & 0,133 \\
\hline Metrodorea stipularis Mart. & 17206 & 96 & 16 & 2,625 & 30 & 6 & 0,239 \\
\hline Zanthoxylum caribaeum Lam.* & 17207 & - & - & - & - & - & - \\
\hline Zanthoxylum fagara (L.) Sargent & 17208 & - & - & - & 9 & 4 & 0,079 \\
\hline Zanthoxylum monogynum A.St.-Hil. & 17209 & 2 & 1 & 0,024 & - & - & - \\
\hline Zanthoxylum rhoifolium Lam. & 16924 & 4 & 4 & 0,042 & 9 & 6 & 0,054 \\
\hline \multicolumn{8}{|l|}{ SALICACEAE } \\
\hline Casearia arborea (L.C.Rich.) Urb. & 12202 & 1 & 1 & 0,005 & - & - & - \\
\hline Casearia decandra Jacq. & 17105 & 4 & 2 & 0,048 & 8 & 5 & 0,023 \\
\hline Casearia lasiophylla Eichler & 17106 & - & - & - & 19 & 8 & 0,100 \\
\hline Casearia melliodora Eichler* & 17108 & - & - & - & - & - & - \\
\hline Casearia obliqua Spreng. & 17220 & 1 & 1 & 0,123 & 12 & 7 & 0,098 \\
\hline Casearia sylvestris Sw. & 17109 & 2 & 1 & 0,017 & 16 & 8 & 0,093 \\
\hline Xylosma prockia (Turcz.) Turcz. & 17658 & - & - & - & 2 & 2 & 0,007 \\
\hline \multicolumn{8}{|l|}{ SAPINDACEAE } \\
\hline Cupania ludowigii Somner \& Ferruci & 16600 & 1 & 1 & 0,050 & 5 & 1 & 0,032 \\
\hline Cupania vernalis Cambess. & 17210 & 7 & 5 & 0,045 & 19 & 7 & 0,093 \\
\hline Diatenopteryx sorbifolia Radlk. & 17211 & 7 & 5 & 0,760 & 5 & 2 & 0,037 \\
\hline Matayba juglandifolia (Cambess.) Radlk. & 16601 & - & - & - & 1 & 1 & 0,005 \\
\hline \multicolumn{8}{|l|}{ SAPOTACEAE } \\
\hline Chrysophyllum gonocarpum (Mart. \& Eichler) Engl. & 17213 & 2 & 2 & 0,007 & - & - & - \\
\hline Chrysophyllum marginatum (Hook. \& Arnot) Radlk.* & 12295 & - & - & - & - & - & - \\
\hline \multicolumn{8}{|l|}{ SIMAROUBACEAE } \\
\hline Picrasma crenata (Vell.) Engl. & 17148 & 6 & 6 & 0,122 & 8 & 3 & 0,192 \\
\hline \multicolumn{8}{|l|}{ SIPARUNACEAE } \\
\hline Siparuna brasiliensis (Spreng.) A.DC.* & 17156 & - & - & - & - & - & - \\
\hline Siparuna guianensis Aublet* & 12472 & - & - & - & - & - & - \\
\hline Siparuna reginae (Tul.) A.DC. & 17157 & 6 & 4 & 0,054 & - & - & - \\
\hline \multicolumn{8}{|l|}{ SOLANACEAE } \\
\hline Aureliana velutina Sendtn. & 17215 & 2 & 1 & 0,004 & - & - & - \\
\hline Cestrum schlechtendalii G.Don & 17216 & 11 & 4 & 0,176 & 7 & 3 & 0,080 \\
\hline Solanum cernuum Vell. & 17217 & - & - & - & 3 & 3 & 0,007 \\
\hline Solanum granuloso-leprosum Dunal* & 15478 & - & - & - & - & - & - \\
\hline Solanum leucodendron Sendtn. & 17218 & 2 & 1 & 0,177 & 2 & 2 & 0,006 \\
\hline Solanum pseudoquina A.St.-Hil. & 17219 & 3 & 3 & 0,049 & - & - & - \\
\hline \multicolumn{8}{|l|}{ STYRACACEAE } \\
\hline Styrax camporum Pohl* & 17053 & - & - & - & - & - & - \\
\hline Styrax latifolius Pohl & 17221 & 2 & 2 & 0,051 & 5 & 3 & 0,025 \\
\hline \multicolumn{8}{|l|}{ SYMPLOCACEAE } \\
\hline Symplocos lanceolata (Mart.) A.DC.* & 16985 & - & - & - & - & - & - \\
\hline \multicolumn{8}{|l|}{ THYMELAEACEAE } \\
\hline Daphnopsis brasiliensis Mart. \& Zucc. & 17059 & - & - & - & 2 & 2 & 0,006 \\
\hline Daphnopsis fasciculata (Meisn.) Nevling & 16939 & - & - & - & 3 & 1 & 0,012 \\
\hline \multicolumn{8}{|l|}{ URTICACEAE } \\
\hline Boehmeria caudata $\mathrm{Sw}$. & 17107 & 1 & 1 & 0,002 & - & - & - \\
\hline Cecropia glaziovii Snethl. & 16403 & 2 & 2 & 0,106 & 6 & 3 & 0,131 \\
\hline Cecropia pachystachya Trécul* & 16772 & - & - & - & - & - & - \\
\hline Coussapoa microcarpa (Schott) Rizz. & 17082 & 7 & 6 & 3,138 & 1 & 1 & 0,025 \\
\hline Urera caracasana (Jacq.) Gaudich. ex Griseb.* & 17769 & - & - & - & - & - & - \\
\hline
\end{tabular}


continuação

\begin{tabular}{|c|c|c|c|c|c|c|c|}
\hline \multirow[t]{2}{*}{ Famílias e espécies } & \multirow[b]{2}{*}{$\mathrm{Nr}$} & \multicolumn{3}{|c|}{ Interior $(n=18)$} & \multicolumn{3}{|c|}{$\operatorname{Borda}(n=12)$} \\
\hline & & $\mathrm{N}$ & $\mathrm{P}$ & $\mathrm{AB}$ & $\mathrm{N}$ & $\mathrm{P}$ & $\mathrm{AB}$ \\
\hline \multicolumn{8}{|l|}{ VOCHYSIACEAE } \\
\hline Qualea multiflora Mart.* & 16304 & - & - & - & - & - & - \\
\hline Vochysia magnifica Warm. & 17376 & 3 & 1 & 0,045 & 3 & 2 & 0,026 \\
\hline Vochysia oppugnata Warm. & 17225 & 2 & 2 & 0,057 & - & - & - \\
\hline Vochysia schwackeana Warm. & 17224 & 1 & 1 & 0,011 & 1 & 1 & 0,156 \\
\hline Vochysia tucanorum Mart.* & 17227 & - & - & - & - & - & - \\
\hline
\end{tabular}

* Espécies registradas apenas no levantamento florístico.

* Species registered only in the floristic survey.

Tabela 2. Variáveis estruturais da comunidade arbórea nas 12 e 18 parcelas utilizadas para amostrar, respectivamente, a Borda e o Interior do fragmento de floresta semidecídua em Piedade do Rio Grande, MG. Os valores são médias \pm desvios padrão, seguidos de comparações pelo teste de $t$ de Student.

Table 2. Structural variables of the tree community in the 12 and 18 plots used to survey, the Edge and Interior, respectively, of the fragment of tropical semideciduous forest in Piedade do Rio Grande, SE Brazil. Values are means \pm standard deviations, followed by Student $t$ test comparisons.

\begin{tabular}{|c|c|c|c|c|}
\hline Variáveis & Borda & Interior & $t$ & $P$ \\
\hline Densidade (árvores ha-1) & $2031,0 \pm 500,0$ & $1115,0 \pm 302,0$ & 5,69 & 0,0001 \\
\hline Área basal $\left(\mathrm{m}^{2} \mathrm{ha}^{-1}\right)$ & $37,8 \pm 15,3$ & $45,4 \pm 31,0$ & 0,89 & 0,3800 \\
\hline Diâmetro médio (cm) & $12,2 \pm 2,0$ & $16,3 \pm 3,0$ & 4,50 & $<0,0001$ \\
\hline Diâmetro máximo (cm) & $53,1 \pm 15,3$ & $73,0 \pm 35,4$ & 2,11 & 0,0460 \\
\hline Altura média (m) & $7,3 \pm 1,0$ & $9,6 \pm 1,1$ & 5,74 & $<0,0001$ \\
\hline Altura máxima (m) & $17,9 \pm 6,0$ & $23,3 \pm 6,5$ & 2,33 & 0,0290 \\
\hline
\end{tabular}

As quatro CCAs apresentaram autovalores muito baixos para os dois primeiros eixos, isto é, todos $<0,35$ (tabela 5). Isto significa que os gradientes são curtos em todos os casos, ou seja, há pouca substituição de espécies e a maioria delas se distribui ao longo dos gradientes variando apenas sua abundância (ter Braak 1995). As CCAs ambiental e espacial explicaram proporções semelhantes da variação total das espécies, entre $21-22 \%$, o que salienta que a proximidade espacial tem um peso semelhante ao das variáveis ambientais quando se procura explicar a distribuição da abundância das árvores no fragmento. Além disso, conforme indica a figura 4 , (a) apenas $12,68 \%$ da variação total é puramente ambiental e independente do espaço (CCA3); (b) $9,24 \%$ da variação é indistintamente espacial e ambiental (CCA1 - 3 ou CCA2 - 4), ou seja, deve-se à estrutura espacial do próprio ambiente; (c) 11,84\% da variação é puramente espacial e independente do ambiente (CCA4). Em decorrência disso, pouco mais de um terço da variação total $(33,77 \%)$ foi explicada por ambiente e espaço em conjunto (CCA1 +4 ou CCA2 + 3), restando (d) 66,23\% de variação das espécies que é estocástica ou não explicável pelas variáveis disponíveis. Esta expressiva variância remanescente é comum em dados de vegetação e não prejudica a significância das relações espécie-ambiente (ter Braak 1988). Com efeito, os dois primeiros eixos das quatro CCAs explicaram proporções elevadas das variações da correlação espécie-ambiente, $>50 \%$ e $>80 \%$ no primeiro e segundo eixos, respectivamente (tabela 5). As correlações de Pearson entre espécies e variáveis ambientais e espaciais também foram elevadas nos dois primeiros eixos, variando entre 0,80 e 0,93 . Além disso, em todas as CCAs, os testes de permutação de Monte Carlo indicaram diferenças altamente significativas entre as correlações encontradas e as geradas pelo acaso, tanto para o primeiro eixo canônico como para o conjunto de eixos canônicos (tabela 5).

Entre as variáveis ambientais, a cota se destaca como mais fortemente correlacionada com o primeiro eixo das duas CCAs ambientais, mas também tem peso expressivo do segundo eixo da CCA1 (tabela 5). O fator de borda tem correlações mais fortes com o segundo eixo da CCA1 e ambos os eixos da CCA3. A saturação por bases $(\mathrm{V})$ produziu correlações relativamente mais fracas na CCA1 $(c a \pm 0,45)$, mas alcançou valor 
expressivo no segundo eixo da CCA3. As variáveis espaciais, $\mathrm{y}^{2}$ e $\mathrm{y}^{3}$, produziram correlações entre $\pm 0,5 \mathrm{e}$ $\pm 0,85$ em todos os casos exceto o de $\mathrm{y}^{3}$ no segundo eixo da CCA2, que ficou abaixo de $\pm 0,4$. É notório que ambas as variáveis espaciais selecionadas pela sua correlação significativa com a variância da matriz de espécies tenham sido derivadas da dimensão correspondente ao eixo norte-sul e ao sentido da declividade predominante na encosta. Isto sugere que o efeito da proximidade das plantas sobre sua própria distribuição de abundâncias foi significativo no sentido paralelo à declividade, mas não pôde ser detectado no sentido perpendicular à mesma. A redundância de y com a cota pode, provavelmente, explicar boa parte das variações ambientais espacialmente estruturadas representadas pelo setor (b) da figura 3 .
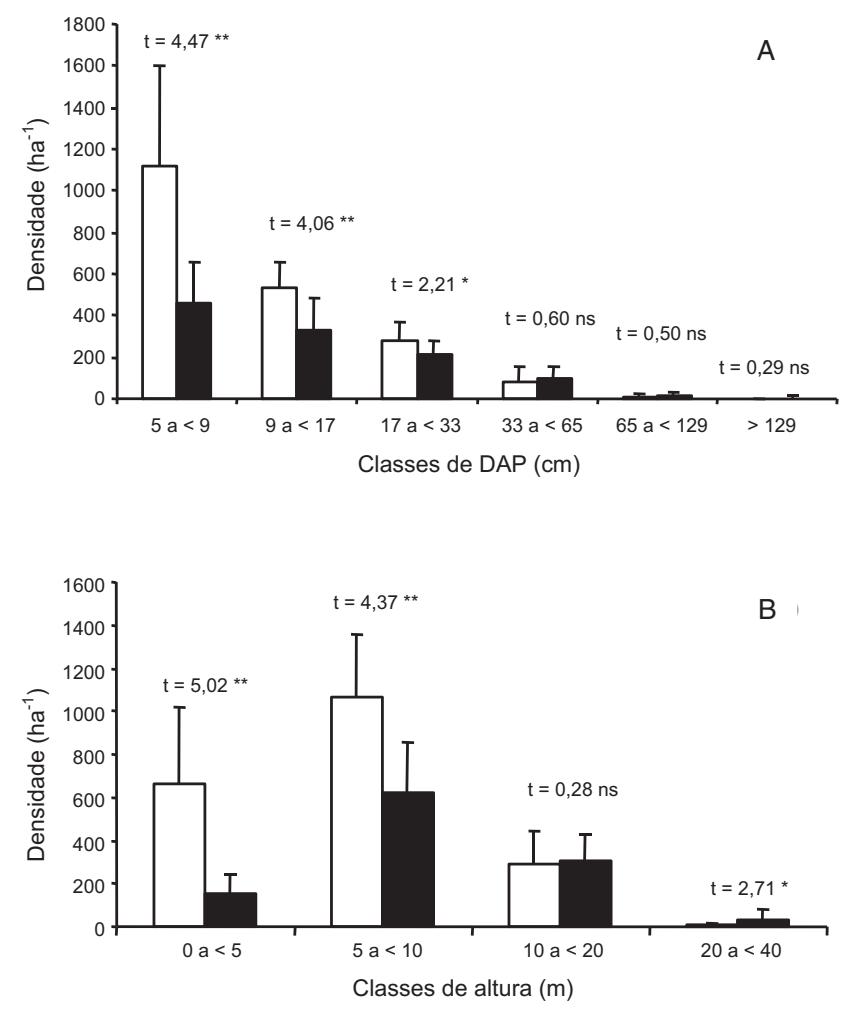

Figura 2. Distribuição da densidade de árvores $\geq 5 \mathrm{~cm}$ de DAP em classes de diâmetro (A) e de altura (B) nas 12 e 18 parcelas utilizadas, respectivamente, para amostrar a Borda (barras vazias) e o Interior (barras cheias) do fragmento de floresta semidecídua em Piedade do Rio Grande, MG.

Figure 2. Tree density distribution of trees $\geq 5 \mathrm{~cm}$ dbh into classes of diameter (A) and height (B) in the 12 and 18 sample plots used to survey, respectively, the Edge (open bars) and Interior (closed bars) of the fragment of semideciduous forest in Piedade do Rio Grande, SE Brazil.
Para representar graficamente a análise, foi escolhida a CCA1 para explorar apenas os efeitos das variáveis ambientais. Os diagramas da figura 5 mostram a ordenação de espécies e parcelas em separado, para maior clareza. As coordenadas de ordenação das espécies e parcelas representam o ótimo aproximado de uma distribuição unimodal das mesmas no espaço multidimensional definido pelas variáveis ambientais. Estas, por sua vez, são representadas por retas divergentes indicando a direção predominante da magnitude crescente de cada variável no espaço de ordenação (ter Braak 1988). A ordenação sugere forte separação entre parcelas de Borda e Interior. As correlações com as três variáveis ambientais são muito claras, assim como o efeito borda-interior. A CCA sugere um gradiente onde espécies como Anaxagorea silvatica, Virola bicuhyba, Metrodorea stipularis, Trichilia catigua, Galipea jasminiflora, Rollinia sylvatica, Prunus myrtifolia, Cestrum schlechtendalii, Pisonia zapallo e Diatenopteryx sorbifolia tendem a ocorrer em maior abundância no interior, enquanto espécies como Hyptidendron asperrimum, Clethra scabra, Myrcia splendens, Casearia sylvestris, Vismia brasiliensis, Machaerium villosum, Protium

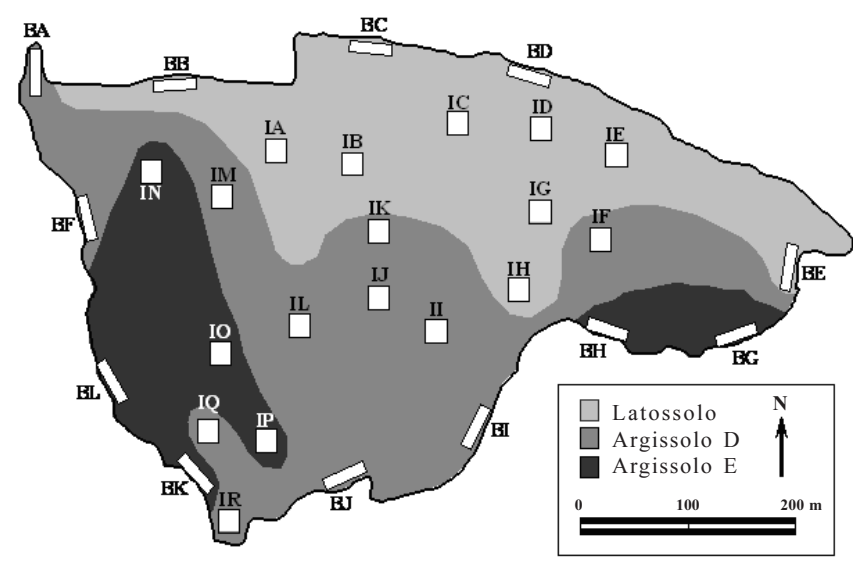

Figura 3. Mapa do fragmento de floresta semidecídua inventariado em Piedade do Rio Grande, MG, mostrando a distribuição dos subgrupos de solo e das 30 parcelas de $400 \mathrm{~m}^{2}$, com as respectivas identificações por códigos de duas letras.

Figure 3. Map of the fragment of tropical semideciduous forest surveyed in Piedade do Rio Grande, SE Brazil, showing the distribution of the soil subgroups and of the 30 sample plots of $400 \mathrm{~m}^{2}$, with their respective identification by twoletters codes. 
widgrenii, Myrsine umbellata, Piptocarpha axillaris e Croton floribundus concentram-se mais na borda.

As comparações das abundâncias das espécies entre as parcelas da Borda e Interior (tabela 6) mostram que metade das 46 espécies foi significativamente mais abundante em um dos estratos, sendo 19 na Borda e quatro no Interior. Tais espécies foram também distribuídas no diagrama da CCA nos extremos da dicotomia borda-interior (figura 5). Dentre as mesmas 46 espécies, 19 mostraram alguma correlação significativa entre suas abundâncias nas parcelas e as variáveis cota e saturação por bases (tabela 6). Para cota, houve 12 correlações positivas e três negativas e, para saturação por bases, cinco positivas e duas

Tabela 3. Variáveis relacionadas à diversidade de espécies nas 12 e 18 parcelas utilizadas para amostrar, respectivamente, a Borda e o Interior do fragmento de floresta semidecídua em Piedade do Rio Grande, MG. As comparações foram pelo teste de $t$ de Student para densidade de espécies e $t$ de Hutcheson para $H^{\prime}$. A densidade de espécies é expressa por médias \pm desvios padrão.

Table 3. Variables related to species diversity in the 12 and 18 plots used to survey, the Edge and Interior, respectively, of the fragment of tropical semideciduous forest in Piedade do Rio Grande, SE Brazil. A Student $t$ test comparisons were performed for species density and a Hutcheson $t$ test for $H^{\prime}$. Species density is expressed by means \pm standard deviations.

\begin{tabular}{lccccc}
\hline Variáveis & Total & Borda & Interior & $t$ & $P$ \\
\hline Número de indivíduos nas parcelas & 1779 & 976 & 803 & - & - \\
Número de espécies nas parcelas & 174 & 135 & 120 & - & - \\
Número de espécies no lev. florístico total & 269 & - & - & - & - \\
Densidade de espécies nas parcelas & - & $31,8 \pm 4,4$ & $22,2 \pm 4,6$ & 5,71 & $<0,0001$ \\
Índice de Shannon, $H$ ' (nats indivíduo-1) & 4,415 & 4,264 & 3,942 & 5,41 & $<0,0010$ \\
Equabilidade de Pielou, $J$ & 0,855 & 0,867 & 0,821 & - & - \\
Estimador "jack-knife" de 1 $1^{\mathrm{a}}$ ordem & 213,7 & 183,7 & 162,6 & & - \\
Estimador "jack-knife" de 2 $2^{\mathrm{a}}$ ordem & 220,4 & 201,2 & 179,1 & & - \\
\hline
\end{tabular}

Tabela 4. Variáveis topográficas de 30 parcelas de $400 \mathrm{~m}^{2}$ empregadas para inventariar o fragmento de floresta semidecídua em Piedade do Rio Grande, MG, e variáveis químicas e texturais de 30 amostras do solo superficial ( 0 a $20 \mathrm{~cm}$ de profundidade) coletadas nas parcelas. Os valores são médias \pm desvios padrão das $n$ amostras de cada uma dos três subgrupos de solo. Onde testes de $F$ indicaram diferenças significativas entre os três solos, as médias seguidas de letras diferentes são significativamente diferentes em testes de Tukey-Kramer.

Table 4. Topographic variables of 30 plots of $400 \mathrm{~m}^{2}$ of area used to survey the fragment of tropical semideciduous forest in Piedade do Rio Grande, SE Brazil, and chemical and textural variables of 30 soil samples collected from each plot at 0-20 cm of depth. Values are means \pm standard deviations of $n$ replications of each soil sub-group. Where $F$ tests indicated significant differences among soils means followed by different letters differ significantly in Tukey-Kramer tests.

\begin{tabular}{|c|c|c|c|c|c|}
\hline \multirow{3}{*}{$\begin{array}{l}\text { Variáveis } \\
\text { Cota média* }\left(10^{3} \mathrm{~m}\right)\end{array}$} & \multirow{2}{*}{$\begin{array}{l}\text { Latossolo } \\
(n=12)\end{array}$} & \multirow{2}{*}{$\begin{array}{l}\text { Argissolo D } \\
\quad(n=10)\end{array}$} & \multirow{2}{*}{$\begin{array}{l}\text { Argissolo E } \\
\quad(n=8)\end{array}$} & \multicolumn{2}{|c|}{ ANOVA } \\
\hline & & & & $F$ & $P$ \\
\hline & $125,2 \pm 25 \mathrm{a}$ & $93,5 \pm 29 b$ & $85,4 \pm 23 b$ & 6,47 & 0,0050 \\
\hline Desnível (m) & $6,0 \pm 2,7$ & $9,5 \pm 5,2$ & $9,9 \pm 3,9$ & 2,97 & 0,0680 \\
\hline $\mathrm{pH} \mathrm{em} \mathrm{H}_{2} \mathrm{O}$ & $4,35 \pm 0,3 b$ & $4,50 \pm 0,3 b$ & $5,52 \pm 0,3 \mathrm{a}$ & 40,28 & $<0,0001$ \\
\hline $\mathrm{P}-\operatorname{Mehlich}\left(\mathrm{mg} \mathrm{dm}^{-3}\right)$ & $1,00 \pm 0,0$ & $1,09 \pm 0,3$ & $1,28 \pm 0,5$ & 2,09 & 0,1430 \\
\hline $\left.\mathrm{K}^{+}(\mathrm{mg} \mathrm{dm})^{-3}\right)$ & $43,00 \pm 16 b$ & $54,00 \pm 25 b$ & $175,00 \pm 59 a$ & 38,32 & $<0,0001$ \\
\hline $\mathrm{Ca}^{2+}\left(\mathrm{cmol}_{\mathrm{c}} \mathrm{dm}^{-3}\right)$ & $0,90 \pm 0,3 b$ & $1,14 \pm 0,4 b$ & $4,51 \pm 2,2 \mathrm{a}$ & 27,59 & $<0,0001$ \\
\hline $\mathrm{Mg}^{2+}\left(\mathrm{cmol}_{\mathrm{c}} \mathrm{dm}^{-3}\right)$ & $0,57 \pm 0,4 \mathrm{a}$ & $0,95 \pm 0,5 b$ & $2,77 \pm 0,5 \mathrm{a}$ & 49,37 & $<0,0001$ \\
\hline $\mathrm{Al}^{3+}\left(\mathrm{cmol}_{\mathrm{c}} \mathrm{dm}^{-3}\right)$ & $1,25 \pm 0,4 \mathrm{a}$ & $0,80 \pm 0,3 b$ & $0,07 \pm 0,1 \mathrm{c}$ & 28,17 & $<0,0001$ \\
\hline $\mathrm{V}$ - saturação por bases $(\%)$ & $15,00 \pm 6,1 \mathrm{c}$ & $26,00 \pm 9,6 b$ & $69,00 \pm 12 \mathrm{a}$ & 83,59 & $<0,0001$ \\
\hline Matéria orgânica (dag $\left.\mathrm{kg}^{-1}\right)$ & $4,45 \pm 0,7 \mathrm{a}$ & $3,60 \pm 0,5 b$ & $3,9 \pm 1,0 \mathrm{ab}$ & 4,10 & 0,0280 \\
\hline Areia $(\%)$ & $26,16 \pm 3,4 b$ & $35,45 \pm 8,8 \mathrm{a}$ & $32,57 \pm 6,7 \mathrm{a}$ & 5,94 & 0,0070 \\
\hline Silte $(\%)$ & $14,00 \pm 3,6 b$ & $17,63 \pm 3,8 b$ & $24,71 \pm 2,9 \mathrm{a}$ & 19,83 & $<0,0001$ \\
\hline Argila (\%) & $59,83 \pm 4,1 \mathrm{a}$ & $46,90 \pm 8,9 b$ & $42,71 \pm 8,1 b$ & 15,73 & $<0,0001$ \\
\hline
\end{tabular}


Tabela 5. Resumo dos resultados das análises de correspondência canônica da abundância de 51 espécies em 30 parcelas de floresta semidecídua em Piedade do Rio Grande, MG, em interação com variáveis ambientais e espaciais, e dos testes de permutação de Monte Carlo correspondentes. São fornecidos resultados para os dois primeiros eixos de ordenação e resultados globais que aparecem centralizados entre os dois eixos.

Table 5. Synthetic results of canonical correspondence analyses of the abundance of 51 species in 30 plots of tropical semideciduous forest in Piedade do Rio Grande, SE Brazil, interactive with environmental and spatial variables, and of their corresponding Monte Carlo permutation tests. Results are given for the first two ordination axes together with global results, which appear centralized between the two axes.

\begin{tabular}{|c|c|c|c|c|c|c|c|c|c|}
\hline \multirow{2}{*}{$\begin{array}{l}\text { CCAs* } \\
\text { Eixos: }\end{array}$} & & \multicolumn{2}{|c|}{ 1:Ambiente } & \multicolumn{2}{|c|}{ 2: Espaço } & \multicolumn{2}{|c|}{$\begin{array}{l}\text { 3: Ambiente } \\
\text { - Espaço }\end{array}$} & \multicolumn{2}{|c|}{$\begin{array}{l}\text { 4: Ambiente } \\
\text { - Espaço }\end{array}$} \\
\hline & & 1 & 2 & 1 & 2 & 1 & 2 & 1 & 2 \\
\hline Autovalores & & 0,299 & 0,159 & 0,340 & 0,161 & 0,159 & 0,086 & 0,169 & 0,114 \\
\hline Correlações espécie $\times$ ambien & aço & 0,879 & 0,805 & 0,926 & 0,830 & 0,823 & 0,876 & 0,876 & 0,824 \\
\hline \multicolumn{10}{|c|}{ Variância percentual cumulativa (\%): } \\
\hline de dados das espécies & & 12,6 & 19,2 & 14,3 & 21,1 & 8,4 & 13,0 & 9,1 & 15,2 \\
\hline de relações espécie $\times$ ambi & paço & 57,3 & 87,6 & 67,8 & 100,0 & 52,5 & 80,8 & 59,8 & 100,0 \\
\hline Soma de autovalores canônicc & & \multicolumn{2}{|c|}{0,522} & \multicolumn{2}{|c|}{0,502} & \multicolumn{2}{|c|}{0,302} & \multicolumn{2}{|c|}{0,282} \\
\hline Variância total explicada (\%): & & \multicolumn{2}{|c|}{21,92} & \multicolumn{2}{|c|}{21,08} & \multicolumn{2}{|c|}{12,68} & \multicolumn{2}{|c|}{11,84} \\
\hline \multicolumn{10}{|c|}{ Testes de permutação de Monte Carlo: } \\
\hline \multirow[t]{2}{*}{ Primeiro eixo canônico: } & $F$ & \multicolumn{2}{|l|}{3,733} & \multicolumn{2}{|l|}{4,506} & \multicolumn{2}{|l|}{2,214} & \multicolumn{2}{|l|}{2,397} \\
\hline & $p$ & \multicolumn{2}{|l|}{0,002} & \multicolumn{2}{|l|}{0,002} & \multicolumn{2}{|l|}{0,004} & \multicolumn{2}{|l|}{0,002} \\
\hline \multirow[t]{2}{*}{ Todos os eixos canônicos: } & $F$ & \multicolumn{2}{|c|}{2,434} & \multicolumn{2}{|c|}{3,607} & \multicolumn{2}{|c|}{1,534} & \multicolumn{2}{|c|}{2,149} \\
\hline & $p$ & \multicolumn{2}{|c|}{0,002} & & 02 & & & & \\
\hline Correlações internas com os ei & & & & & & & & & \\
\hline Saturação por bases (V) & & 0,44 & $-0,46$ & & & $-0,09$ & 0,78 & & \\
\hline Cota média & & $-0,79$ & 0,61 & & & 0,80 & $-0,36$ & & \\
\hline Fator de borda & & $-0,51$ & $-0,84$ & & & 0,72 & 0,67 & & \\
\hline Variável espacial $y^{2}$ & & & & 0,86 & $-0,52$ & & & 0,69 & 0,72 \\
\hline Variável espacial $\mathrm{y}^{3}$ & & & & 0,92 & $-0,38$ & & & 0,83 & 0,55 \\
\hline
\end{tabular}

* Inércia total ou soma de todos os autovalores $=2,381$

* Total inertia or sum of all eigenvalues $=2.381$

negativas. Tais correlações foram coerentes com a distribuição das espécies no diagrama da CCA (figura 5). Das 46 espécies analisadas, 14 (30\%) não mostraram nenhum padrão de distribuição significativamente relacionado com as duas variáveis ambientais nem com a dicotomia borda-interior.

\section{Discussão}

No contexto dos padrões de variações florísticas e ambientais das florestas Atlânticas sensu lato do Sudeste do Brasil descritos por Oliveira Filho \& Fontes (2000), a composição de espécies arbóreas do fragmento estudado em Piedade do Rio Grande pode ser vista como uma expressão de duas transições florísticas: a primeira delas entre florestas ombrófilas e semidecíduas e a segunda entre florestas baixo-montanas e alto-montanas. Há espécies características de florestas ombrófilas, como Coussapoa microcarpa, Sloanea guianensis,
Vochysia schwackeana, Virola bicuhyba, Picrasma crenata e Marlierea excoriata; espécies comuns de florestas semidecíduas, como Machaerium villosum, Ceiba speciosa, Luehea grandiflora, Platypodium elegans e Copaifera langsdorffii; espécies características de florestas alto-montanas, como Capsicodendron dinisii, Clethra scabra, Jacaranda subalpina, Euplassa organensis e Araucaria angustifolia; e espécies típicas de florestas baixomontanas como Protium widgrenii, Vismia brasiliensis, Piptocarpha axillaris e Calyptranthes clusiifolia. A observação é reforçada pelas principais famílias encontradas, pois o perfil florístico do fragmento se aproxima das florestas alto-montanas no expressivo número de espécies das famílias Myrtaceae, Lauraceae, Melastomataceae e Solanaceae. Contudo, a abundância de Fabaceae se opõe ao caráter alto-montano, conferido pelas famílias anteriores (Oliveira Filho \& Fontes 2000). $\mathrm{O}$ fragmento localiza-se em uma vertente com face de 
Tabela 6. Comparações pelo teste de $t$ da abundância média de 46 espécies arbóreas nas 12 parcelas de Borda e 18 de Interior empregadas para inventariar o fragmento de floresta semidecídua em Piedade do Rio Grande, MG, e coeficientes de correlação de Pearson $\left(R_{\mathrm{p}}\right)$ entre a abundância das espécies e as variáveis cota média e saturação por bases $(\mathrm{V})$ nas 30 parcelas. $\mathrm{B} / \mathrm{I}=$ estrato amostral onde a abundância foi maior; $\mathrm{B}=$ Borda; $\mathrm{I}=$ Interior. $\mathrm{ns}=$ não significativo $(P>0,05)$.

Table 6. Comparisons through $t$ tests of the mean abundance of 46 tree species in the 12 Edge plots and 18 Interior plots used to survey the fragment of tropical semideciduous forest in Piedade do Rio Grande, SE Brazil, and Pearson correlation coefficients $\left(R_{\mathrm{p}}\right)$ between the species abundance and the variables mean elevation and soil base saturation $(\mathrm{V})$ in the 30 plots. $\mathrm{B} / \mathrm{I}=$ sample stratum where abundance was higher; $\mathrm{B}=$ Edge; $\mathrm{I}=$ Interior. $\mathrm{ns}=$ non significant $(P>0.05)$.

\begin{tabular}{|c|c|c|c|c|c|c|c|}
\hline \multirow[b]{2}{*}{ Espécie } & \multicolumn{3}{|c|}{ Borda-Interior } & \multicolumn{2}{|c|}{ Cota } & \multicolumn{2}{|c|}{$\mathrm{V}$} \\
\hline & $t$ & $P$ & $\mathrm{~B} / \mathrm{I}$ & $R_{\mathrm{P}}$ & $P$ & $R_{\mathrm{P}}$ & $P$ \\
\hline Anaxagorea silvatica & $-4,89$ & $<10^{-4}$ & $\mathrm{I}$ & $-0,180$ & $\mathrm{~ns}$ & 0,008 & $\mathrm{~ns}$ \\
\hline Bauhinia forficata & 3,72 & 0,001 & B & $-0,374$ & 0,042 & 0,367 & 0,046 \\
\hline Cabralea canjerana & 1,57 & $\mathrm{~ns}$ & & $-0,542$ & 0,002 & 0,129 & $\mathrm{~ns}$ \\
\hline Calyptranthes clusiifolia & 2,34 & 0,050 & $\mathrm{~B}$ & 0,482 & 0,007 & $-0,269$ & $\mathrm{~ns}$ \\
\hline Casearia decandra & 1,68 & $\mathrm{~ns}$ & & $-0,063$ & $\mathrm{~ns}$ & 0,293 & ns \\
\hline Casearia lasiophylla & 5,18 & $<10^{-4}$ & B & $-0,017$ & $\mathrm{~ns}$ & 0,140 & $\mathrm{~ns}$ \\
\hline Casearia obliqua & 3,91 & 0,001 & B & $-0,092$ & $\mathrm{~ns}$ & 0,308 & $\mathrm{~ns}$ \\
\hline Casearia sylvestris & 3,61 & 0,001 & B & 0,487 & 0,006 & $-0,129$ & $\mathrm{~ns}$ \\
\hline Cestrum schlechtendalii & $-0,05$ & $\mathrm{~ns}$ & & $-0,283$ & $\mathrm{~ns}$ & 0,254 & $\mathrm{~ns}$ \\
\hline Clethra scabra & 2,61 & 0,015 & B & 0,356 & 0,050 & $-0,271$ & $\mathrm{~ns}$ \\
\hline Colubrina glandulosa & 0,50 & $\mathrm{~ns}$ & & $-0,219$ & $\mathrm{~ns}$ & $-0,219$ & $\mathrm{~ns}$ \\
\hline Cordia sellowiana & 0,84 & $\mathrm{~ns}$ & & 0,464 & 0,010 & $-0,300$ & $\mathrm{~ns}$ \\
\hline Croton floribundus & 2,74 & 0,011 & B & $-0,283$ & $\mathrm{~ns}$ & 0,012 & ns \\
\hline Croton verrucosus & 1,22 & $\mathrm{~ns}$ & & 0,308 & $\mathrm{~ns}$ & $-0,055$ & $\mathrm{~ns}$ \\
\hline Cryptocarya aschersoniana & $-0,37$ & $\mathrm{~ns}$ & & 0,140 & $\mathrm{~ns}$ & 0,001 & ns \\
\hline Cupania vernalis & 2,30 & 0,029 & B & 0,410 & 0,025 & $-0,305$ & $\mathrm{~ns}$ \\
\hline Diatenopteryx sorbifolia & $-0,28$ & $\mathrm{~ns}$ & & $-0,128$ & $\mathrm{~ns}$ & 0,144 & $\mathrm{~ns}$ \\
\hline Galipea jasminiflora & 1,30 & $\mathrm{~ns}$ & & $-0,032$ & $\mathrm{~ns}$ & $-0,147$ & $\mathrm{~ns}$ \\
\hline Guapira opposita & $-1,76$ & $\mathrm{~ns}$ & & $-0,212$ & $\mathrm{~ns}$ & 0,017 & $\mathrm{~ns}$ \\
\hline Hyeronima alchorneoides & 0,56 & $\mathrm{~ns}$ & & 0,277 & $\mathrm{~ns}$ & $-0,292$ & $\mathrm{~ns}$ \\
\hline Hyptidendron asperrimum & 3,13 & 0,004 & B & 0,271 & $\mathrm{~ns}$ & $-0,022$ & $\mathrm{~ns}$ \\
\hline Ixora brevifolia & 1,01 & $\mathrm{~ns}$ & & 0,440 & 0,015 & $-0,256$ & $\mathrm{~ns}$ \\
\hline Jacaranda macrantha & 1,20 & $\mathrm{~ns}$ & & $-0,108$ & $\mathrm{~ns}$ & 0,183 & $\mathrm{~ns}$ \\
\hline Luehea divaricata & 2,28 & 0,030 & B & 0,261 & $\mathrm{~ns}$ & $-0,114$ & ns \\
\hline Machaerium nictitans & 1,86 & $\mathrm{~ns}$ & & $-0,191$ & $\mathrm{~ns}$ & 0,387 & 0,035 \\
\hline Machaerium villosum & 2,31 & 0,028 & $\mathrm{~B}$ & 0,457 & 0,011 & $-0,246$ & $\mathrm{~ns}$ \\
\hline Marlierea racemosa & 0,96 & $\mathrm{~ns}$ & & 0,359 & 0,050 & $-0,128$ & ns \\
\hline Metrodorea stipularis & $-1,87$ & $\mathrm{~ns}$ & & $-0,140$ & $\mathrm{~ns}$ & 0,254 & $\mathrm{~ns}$ \\
\hline Mollinedia widgrenii & 3,33 & 0,002 & B & $-0,112$ & $\mathrm{~ns}$ & 0,360 & 0,049 \\
\hline Myrcia splendens & 3,30 & 0,003 & B & 0,431 & 0,018 & $-0,193$ & $\mathrm{~ns}$ \\
\hline Myrsine umbellata & 3,11 & 0,004 & B & 0,093 & $\mathrm{~ns}$ & 0,131 & $\mathrm{~ns}$ \\
\hline Ocotea corymbosa & 0,81 & $\mathrm{~ns}$ & & 0,161 & $\mathrm{~ns}$ & $-0,153$ & $\mathrm{~ns}$ \\
\hline Ocotea odorifera & $-0,03$ & $\mathrm{~ns}$ & & 0,404 & 0,027 & $-0,242$ & $\mathrm{~ns}$ \\
\hline Picrasma crenata & 0,28 & $\mathrm{~ns}$ & & $-0,409$ & 0,025 & 0,490 & 0,006 \\
\hline Piptadenia gonoacantha & 3,37 & 0,002 & B & $-0,257$ & $\mathrm{~ns}$ & 0,146 & $\mathrm{~ns}$ \\
\hline Platycyamus regnellii & $-1,73$ & $\mathrm{~ns}$ & & 0,281 & $\mathrm{~ns}$ & $-0,365$ & 0,047 \\
\hline Protium widgrenii & 2,52 & 0,018 & $\mathrm{~B}$ & 0,476 & 0,008 & $-0,247$ & $\mathrm{~ns}$ \\
\hline Prunus myrtifolia & $-2,35$ & 0,026 & I & 0,228 & $\mathrm{~ns}$ & $-0,087$ & $\mathrm{~ns}$ \\
\hline Pseudobombax grandiflorum & $-1,46$ & $\mathrm{~ns}$ & & $-0,135$ & $\mathrm{~ns}$ & 0,258 & $\mathrm{~ns}$ \\
\hline Rollinia laurifolia & 1,96 & $\mathrm{~ns}$ & & 0,155 & $\mathrm{~ns}$ & 0,049 & $\mathrm{~ns}$ \\
\hline Rollinia dolabripetala & 2,34 & 0,027 & $\mathrm{~B}$ & $-0,257$ & $\mathrm{~ns}$ & 0,269 & $\mathrm{~ns}$ \\
\hline Rollinia sylvatica & $-3,19$ & 0,003 & I & 0,036 & $\mathrm{~ns}$ & $-0,071$ & $\mathrm{~ns}$ \\
\hline Tapirira obtusa & 2,23 & 0,034 & & 0,554 & 0,001 & $-0,372$ & 0,044 \\
\hline Trichilia catigua & $-1,48$ & $\mathrm{~ns}$ & & $-0,287$ & $\mathrm{~ns}$ & 0,376 & 0,042 \\
\hline Virola bicuhyba & $-3,80$ & 0,001 & I & 0,246 & $\mathrm{~ns}$ & $-0,062$ & $\mathrm{~ns}$ \\
\hline Zanthoxylum rhoifolium & 2,05 & 0,050 & $\mathrm{~B}$ & 0,302 & $\mathrm{~ns}$ & $-0,001$ & ns \\
\hline
\end{tabular}


exposição voltada para o sul, situação denominada no Brasil de "terreno noruega", sendo este, em comparação com a face norte, mais frio, úmido e pouco ensolarado. Tal situação, segundo Hugget (1995), favorece espécies relativamente menos exigentes de luz e mais exigentes em umidade. É possível que esta particularidade tenha favorecido a ocorrência de espécies características de florestas de maior altitude na região. Semelhante a outras florestas da região situadas em maiores altitudes, o fragmento contém ainda uma expressiva abundância de Orchidaceae (e.g. Maxillaria sp., Oeceoclades maculata (Lindley) Lindley, Corymborkis flava (Swartz) Kuntze, Oncidium spp., Polystachya spp.), Bromeliaceae (e.g. Tillandsia spp. e Billbergia spp.), briófitas e pteridófitas recobrindo os troncos das árvores.

A riqueza de espécies registrada pode ser considerada como relativamente alta no contexto de 20 levantamentos semelhantes realizados na região (Pereira et al. 2007). A diversidade de espécies expressa pelo índice de Shannon $\left(H^{\prime}=4,415\right.$ nats indivíduo $\left.{ }^{-1}\right)$ corresponde ao segundo valor mais elevado dos mesmos levantamentos (Pereira et al. 2007, Dalanesi et al.

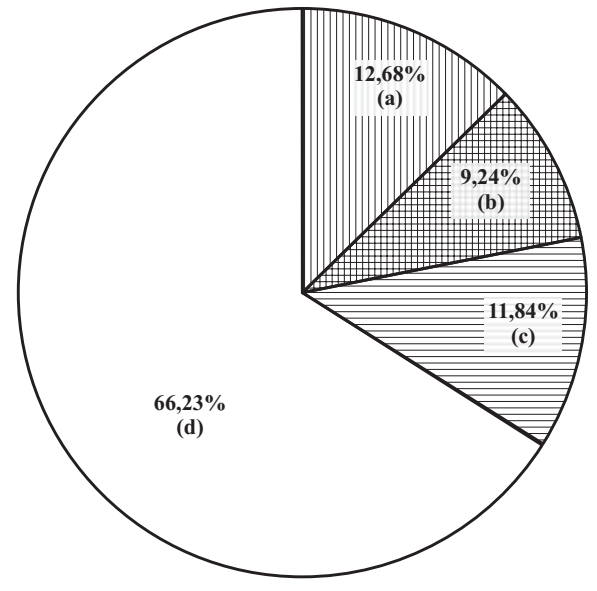

Figura 4. Análises de correspondência canônica (CCA) do número de indivíduos de 51 espécies em 30 parcelas de floresta semidecídua em Piedade do Rio Grande, MG: proporções da variação total da matriz de abundância das espécies explicadas por (a) variáveis ambientais somente, (b) variáveis ambientais e espaciais conjuntamente, (c) variáveis espaciais somente e (d) indeterminada.

Figure 4. Canonical correspondence analysis (CCA) of the distribution of the number of individuals of 51 species in 30 plots of semideciduous forest in Piedade do Rio Grande, SE Brazil: proportions of the total variation of the species abundance matrix explained by (a) environmental variables only, (b) environmental and spatial variables concurrently, (c) spatial variables only, and (d) undetermined.

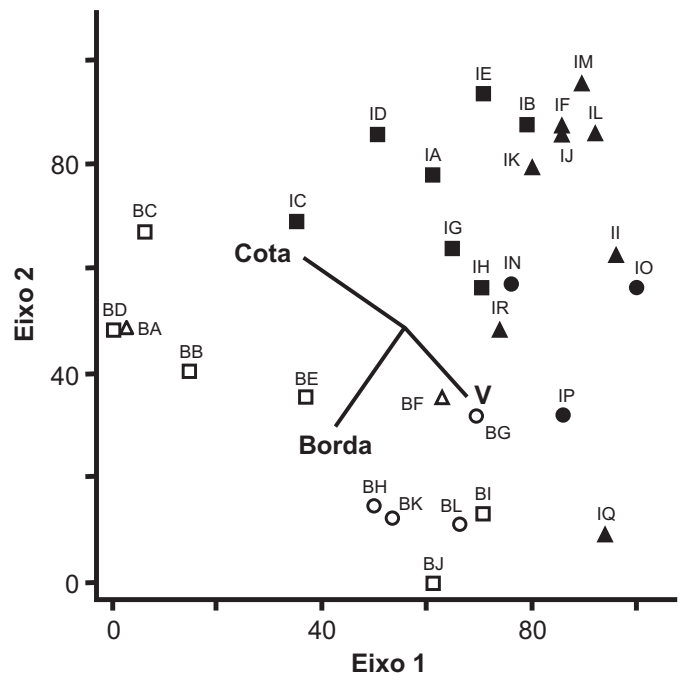

A

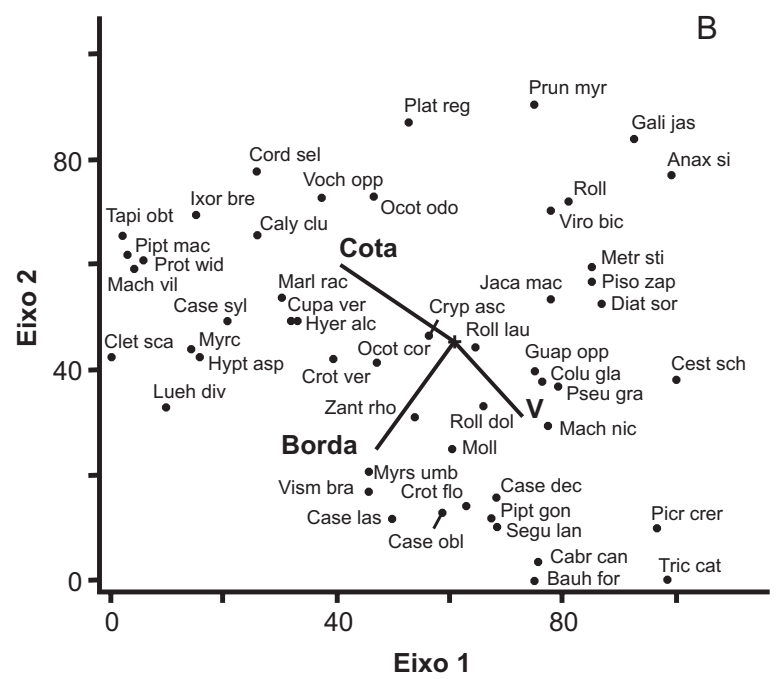

Figura 5. Análise de correspondência canônica (CCA): diagramas de ordenação das parcelas (A) e espécies (B) baseados na distribuição do número de indivíduos de 51 espécies em 30 parcelas de floresta semidecídua em Piedade do Rio Grande, MG, e sua correlação com as três variáveis ambientais utilizadas (retas convergentes). Os subgrupos de solo das parcelas são identificados como: Latossolo $=\mathbf{\square}$ e $\square$; Argissolo $\mathrm{D}=\mathbf{\Lambda}$ e $\triangle$; Argissolo $\mathrm{E}=\bullet$ e $\mathrm{O}$. Símbolos vazios e cheios são parcelas de Borda ou Interior, respectivamente. As parcelas são identificadas conforme figura 3 e as espécies pelos seus nomes abreviados (nomes completos na tabela 6).

Figure 5. Canonical correspondence analysis (CCA): diagrams showing the ordination of plots (A) and species (B) based in the distribution of the number of individuals of 51 species in 30 plots of semideciduous forest in Piedade do Rio Grande, SE Brazil, and their correlation with the three environmental variables used (converging straight lines). Soil subgroups of plots are identified as: Latosol $=\square$ e $\square$; Argisol $\mathrm{D}=\mathbf{\Delta}$ e $\triangle$; and Argisol $\mathrm{E}=\bullet$ e 0 . Open and closed symbols are Edge and Interior plots respectively. Individual plots are identified as in figure 3 and the species by their abbreviated names (full names in table 6). 
2004). Tal fato pode ser atribuído, em grande parte, ao encontro das tipologias florestais discutido acima. Além disso, deve haver também uma expressiva contribuição da considerável heterogeneidade ambiental, propiciada pelo gradiente edáfico e topográfico bem como pelo efeito borda (Metzger 1999, Murcia 1995).

A diferença altitudinal de cerca de $100 \mathrm{~m}$ registrada no fragmento certamente contribuiu para a heterogeneidade ambiental ao propiciar a formação de gradientes edáficos e topográficos com reflexos na estrutura e composição de espécies da comunidade arbórea. De fato, a distribuição dos três subgrupos de solo no fragmento caracterizou uma catena com significativas variações das propriedades químicas e texturais do solo. É comum que conteúdo de água do solo de uma catena cresça do topo para a base da encosta (Resende et al. 1995). Isto se aplica ao presente caso, com Latossolo situado na parte mais alta do terreno. A alta permeabilidade, peculiar à maioria dos Latossolos, é ainda incrementada pela posição topográfica elevada (Curi et al. 1993). Portanto, o déficit hídrico no período mais seco do ano é, provavelmente, mais pronunciado no Latossolo que nos Argissolos, situados mais abaixo na encosta. Nestes últimos, o horizonte B-textural em geral desacelera a percolação da água, mas também aumenta a sua disponibilidade para as plantas durante a estiagem devido à maior capacidade de armazenamento (Buckman \& Brady 1969, Resende et al. 1988). Isto provavelmente explica a concentração de espécies de maior deciduidade na parte mais alta do fragmento, o que é denunciado pelo claro contraste visual do dossel da floresta entre o topo e a encosta durante a estação seca. Também ocorre um incremento em fertilidade química do Latossolo para os Argissolos. Contudo, o incremento em fertilidade do Argissolo D para o Argissolo E só ocorreu em dois setores distintos da encosta. Na calha central da microbacia, o Argissolo D se estende até o fundo do vale, talvez como resultado de uma mais pronunciada erosão e lixiviação que nas encostas vizinhas onde é substituído pelo Argissolo E.

Boa parte da distribuição das espécies mostrou-se espacialmente estruturada e sem conexão com as variáveis ambientais utilizadas, ou seja, foi influenciada pela própria proximidade entre indivíduos co-específicos, resultando em autocorrelação espacial. Aglomerados populacionais são comuns em florestas tropicais e podem se formar tanto devido à dispersão concentrada em curtas distâncias, bem como ao histórico particular de cada peça que compõe o mosaico sucessional da floresta, fenômenos estes que têm pouca ou nenhuma relação com as características do substrato (Oldeman
1990). No entanto, uma outra fração da autocorrelação espacial das espécies foi inseparável da própria variação ambiental e, além disso, concorrente com a disposição espacial do gradiente catenário (norte-sul), sugerindo que os efeitos puramente espaciais participam, de fato, menos que os ambientais na explicação da variância da matriz de espécies.

A distribuição de várias espécies no fragmento foi significativamente correlacionada com as variações da fertilidade dos solos e da elevação topográfica, esta última provavelmente refletindo também um gradiente de disponibilidade de água nos solos. A influência da umidade e fertilidade dos solos na distribuição de espécies arbóreas em florestas tropicais tem largo subsídio na literatura (e.g. Botrel et al. 2002, Clark et al. 1998, Duivervoorden \& Lips 1995, Espírito-Santo et al. 2002, Newbery \& Proctor 1984, Newbery et al. 1986, Oliveira Filho et al. 1994, 1997b, 2001). Na área de estudo, cotas mais elevadas do terreno corresponderam, de modo geral, a sítios com menor estoque de água e nutrientes minerais. Espécies com maior abundância nestes sítios provavelmente apresentam maior capacidade de sobreviver à menor disponibilidade destes recursos. Entre estas estão Calyptranthes clusiifolia, Casearia sylvestris, Clethra scabra, Cordia sellowiana, Cupania vernalis, Ixora brevifolia, Protium widgrenii, Myrcia splendens, Machaerium villosum e Tapirira obtusa, todas elas já correlacionadas por outros autores com sítios de melhor drenagem e, ou, baixa fertilidade química (Botrel et al. 2002, Lorenzi 1992, 1998, Oliveira Filho et al. 1994, Souza et al. 2003). Um número menor de espécies apresentou o padrão oposto, ou seja, foram significativamente mais abundantes nos sítios mais úmidos e férteis da encosta, provavelmente exigindo uma maior disponibilidade de água e, ou, nutrientes minerais. Algumas delas, como Mollinedia widgrenii, Cabralea canjerana, Bauhinia forficata, Machaerium nictitans e Trichilia catigua já haviam sido caracterizadas desta forma por outros autores (Lorenzi 1992, 1998, Oliveira Filho et al. 1994, 1997a, Souza et al. 2003).

Apesar de ter sido detectada uma relação entre a distribuição das espécies e as variações catenárias dos solos, foi o efeito borda que mais fortemente se relacionou com variações espaciais das características da comunidade arbórea, influenciando na estrutura da comunidade e na diversidade e padrão de distribuição de espécies. As bordas de fragmentos florestais são áreas de habitat mais expostas a perturbações externas e possuem, em geral, maior diversidade e densidade de espécies e maior produtividade biológica (Fortin 1992, 
1994). No fragmento estudado, a borda também apresentou maior diversidade em todos os aspectos analisados (riqueza, densidade e eqüabilidade). A natureza transicional dos ambientes de borda parece ser a razão principal deste incremento da diversidade (Fortin 1992, 1994, Murcia 1995, Metzger 1999). A fragmentação florestal aumenta a proporção de áreas de borda, o que ocasiona alterações ambientais importantes. A maior penetração dos raios solares e do vento aumenta a temperatura e a evapotranspiração, reduz a umidade do ar e do solo e cria condições mais favoráveis ao stress hídrico (Kapos et al. 1997). Tudo isto contribui para a instalação de biotas de composição e estrutura distintas daquelas do interior dos fragmentos (Metzger 1999).

A dicotomia em estrutura e composição de espécies da comunidade arbórea entre a borda e o interior de fragmentos florestais também é influenciada pelo histórico do processo de formação e manutenção da borda (Murcia 1995, Oliveira Filho et al. 1997b). Como, no presente caso, as bordas foram estabelecidas entre 1948 e 1952, pode-se afirmar que, após 50 anos, uma comunidade arbórea bastante diferenciada da original já se estabeleceu em resposta às alterações ambientais. Deve-se ter em mente que as alterações ambientais nas bordas são multifatoriais, isto é, envolvem um conjunto de variáveis que incluem condições de luz, temperatura, umidade atmosférica e do solo, exposição ao vento etc. Contudo, a maior exposição à luz tem um peso muito forte. No fragmento estudado, tais alterações ambientais provavelmente explicam a maior densidade de árvores de menor porte, favorecidas pela maior penetração de luz pela borda. Inversamente, a menor densidade de pequenas árvores no interior se deve ao maior sombreamento do subbosque pelas grandes árvores. Espécies encontradas em maior abundância na borda como Bauhinia forficata, Casearia sylvestris, Casearia lasiophylla, Clethra scabra, Croton floribundus, Luehea divaricata, Machaerium villosum, Myrcia splendens, Myrsine umbellata, Piptadenia gonoacantha e Zanthoxylum rhoifolium, são reconhecidas como muito exigentes de luz para seu estabelecimento e crescimento (Botrel et al. 2002, Lorenzi 1992, 1998, Souza et al. 2003). Por outro lado, espécies com distribuição preferencial pelo interior, como Galipea jasminiflora, Prunus myrtifolia e Virola bicuhyba, são reconhecidas como relativamente tolerantes à sombra (Lorenzi 1992, 1998, Oliveira Filho et al. 1994, 1997a). Algumas espécies fugiram ao padrão esperado, como Mollinedia widgrenii e
Calyptranthes clusiifolia, que foram significativamente mais abundantes nas bordas apesar de serem mais comuns no sub-bosque sombrio das florestas da região (Oliveira Filho et al. 1994). No entanto, foi observado no campo que a grande maioria das árvores destas espécies estavam estabelecidas no ambiente mais sombrio adjacente às bordas e não nas bordas em si. Portanto, outros fatores, tais como dispersão ou condições luminosas particulares, devem estar envolvidos na distribuição preferencial destas espécies em um hábitat tão particular.

Como é de praxe em estudos do gênero, ainda restou uma proporção das variações da matriz de abundância das espécies que não pôde ser explicada pelo substrato, pelo efeito borda e nem pela autocorrelação espacial. Esta variação remanescente é muito maior que a explicada e não deve ser meramente desprezada como 'ruído'. Ela é relevante e, para explicá-la, só podemos, infelizmente, especular sobre o papel de variáveis diferenciadoras desconhecidas ou então sobre um universo neutro onde eventos estocásticos governariam a dinâmica de indivíduos igualmente adaptáveis aos habitats em questão (Hubbell 2001). Estas especulações só evidenciam o quanto ainda está longe uma compreensão mais completa da distribuição e diversidade de espécies em florestas tropicais.

Os padrões de diferenciação interna das características da comunidade arbórea do fragmento estudado refletem considerável heterogeneidade ambiental que testemunha a riqueza e complexidade da primitiva cobertura florestal contínua na região. A fragmentação florestal trouxe a intromissão do efeito borda, que incrementou fortemente a heterogeneidade ambiental pré-existente vinculada às variações do substrato. Este fato salienta a importância do tamanho dos fragmentos florestais para promover a conservação de amostras das comunidades primitivas, tamanho este que dever ser tanto maior quanto maior for a heterogeneidade do substrato em que se desenvolve a floresta a ser conservada.

Agradecimentos - Este trabalho integrou o subprojeto 'Estratégias para conservação e manejo da biodiversidade em fragmentos de florestas semidecíduas' executado pela Embrapa Recursos Genéticos, a Universidade Federal de Lavras (UFLA) e Universidade de Brasília (UnB) e integrante do Projeto de Conservação e Utilização Sustentável da Diversidade Biológica Brasileira (Probio). Os autores agradecem às taxonomistas Inês Cordeiro, Maria Lúcia Kawasaki e Lúcia Rossi, pelo atencioso auxílio na identificação do material botânico. 


\section{Referências Bibliográficas}

APG. 2003. An update of the Angiosperm Phylogeny Group classification for the orders and families of flowering plants: APG II. Botanical Journal of the Linnean Society 141:399-436.

BORCARD, D., LEGENDRE, P. \& DRAPEAU, P. 1992. Partialling out the spatial component of ecological variation. Ecology 73:1042-1055.

BOTREL, R.T., OLIVEIRAFILHO, A.T., RODRIGUES, L.A. \& CURI, N. 2002. Influência do solo e topografia sobre as variações da composição florística e estrutura da comunidade arbóreo-arbustiva de uma floresta estacional semidecidual em Ingaí, MG. Revista Brasileira de Botânica 25:195-213.

BRASIL. 1992. Normais climatológicas (1961-1990). Departamento Nacional de Meteorologia, Brasília.

BROWER, J.E. \& ZAR, J.H. 1984. Field and laboratory methods for general ecology. W.M.C. Brow, Dubuque.

BUCKMAN, H.O. \& BRADY, N.C. 1969. The nature and properties of soils. Macmillan, London.

CETEC - Fundação Centro Tecnológico de Minas Gerais. 1983. Diagnóstico ambiental do Estado de Minas Gerais. Séries de publicações Técnicas. Belo Horizonte.

CLARK, D.B., CLARK, D.A. \& READ, J.M. 1998. Edaphic variation and the mesoscale distribution of tree species in a neotropical rain forest. Journal of Ecology $86: 101-112$

CURI, N., LARACH, J.O.I, KÄMPF, N., MONIZ, A.C. \& FONTES, L.E.F. 1993. Vocabulário de ciência do solo. Campinas.

DALANESI, P.E., OLIVEIRAFILHO,A.T. \& FONTES, M.A.L. 2004. Flora e estrutura do componente arbóreo da floresta do Parque Florestal Quedas do Rio Bonito, Lavras, MG, e correlações entre distribuição das espécies e variáveis ambientais. Acta Botanica Brasilica 18:737-757.

DUIVERVOORDEN, J.F. \& LIPS, J.M. 1995. A land-ecological study of soils, vegetation, and plant diversity in Colombian Amazonia. Tropenbos series $12.1^{\text {st }}$ ed., The Tropenbos Foundation, Wageningen.

EMBRAPA - Empresa Brasileira de Pesquisa Agropecuária, Centro Nacional de Pesquisa de Solos. 1997. Manual de métodos de análises de solo. $2^{\mathrm{a}}$ ed., Embrapa, Rio de Janeiro.

EMBRAPA - Empresa Brasileira de Pesquisa Agropecuária, Centro Nacional de Pesquisa de Solos. 1999. Sistema brasileiro de classificação de solos. $1^{\mathrm{a}}$ ed., Embrapa, Rio de Janeiro.

ESPÍRITO-SANTO, F.D.B., OLIVEIRA FILHO, A.T., MACHADO, E.L.M., SOUZA, J.S., FONTES, M.A.L. \& MARQUES, J.J.G.S.M. 2002. Variáveis ambientais e a distribuição de espécies arbóreas em um remanescente de Floresta Estacional Semidecídua Montana no campus da Universidade Federal de Lavras, MG. Acta Botanica Brasilica 16:331-356.
FORTIN, M.J. 1992. Detection of ecotones: definition and scaling factors. Tese de doutorado, University of New York, New York.

FORTIN, M.J. 1994. Edge detection algorithms for twodimensional ecological data. Ecology 75: 956-965.

HELTSCHE, J.F. \& FORRESTER, N.E. 1983. Estimating species richness using the jackknife procedure. Biometrics 39:1-12.

HUBBELL, S. P. 2001. The unified neutral theory of biodiversity and biogeography. Princeton Univ. Press, New Jersey.

HUGGET, R.J. 1995. Geoecology, an evolutionary approach. Routledge, London.

KAPOS, V., CAMARGOS, J.L.C. \& DANDE, G. 1997. Edge related changes in environment and plant response due to forest fragmentation in Central Amazonia. In Tropical forest remnants: ecology, management and conservation of fragmented communities (W.F. Laurance \& R.O. Bierregaard, eds.). The University of Chicago Press, Chicago, p.45-54.

LORENZI, H. 1992. Árvores brasileiras: manual de identificação e cultivo de plantas arbóreas nativas do Brasil. v.1, Editora Plantarum, Nova Odessa.

LORENZI, H. 1998. Árvores brasileiras: manual de identificação e cultivo de plantas arbóreas nativas do Brasil. v.2, Editora Plantarum, Nova Odessa.

METZGER, J.P. 1999. Estrutura da paisagem e fragmentação: análise bibliográfica. Anais da Academia Brasileira de Ciências 71:445-463.

MURCIA, C. 1995. Edges effects in fragmented forest: implications for conservation. Trends in Ecology and Evolution 10:58-62.

NEWBERY, D.McC. \& PROCTOR, J. 1984. Ecological studies in four contrasting lowland rain forests in Gunugu Mulu National Park, Sarawak. IV. Association between tree distribution and soil factors. Journal of Ecology 72:475-493.

NEWBERY, D.McC., GARTLAN, J.S., MCKEY, D.B. \& WATERMAN, P.G. 1986. The influence of drainage and soil phosphorus on the vegetation of Douala-Edea Forest reserve, Cameroun. Vegetatio 65:149-162.

OLDEMAN, R. A. A. 1990. Dynamics in tropical rain forests. In Tropical forests - Botanical dynamics, speciation and diversity (L.B. Holm-Nielsen, I. C. Nielsen \& H. Balslev, eds.). Academic Press, London, pp. 3-21.

OLIVEIRA FILHO, A.T. \& FONTES M.A.L. 2000. Patterns of floristic differentiation among Atlantic forests in southeastern Brazil, and the influence of climate. Biotropica 32:793-810.

OLIVEIRAFILHO, A.T., VILELA, E.A., CARVALHO, D.A. \& GAVILANES, M.L. 1994. Effects of soils and topography on the distribution of tree species in a tropical riverine forest in south-eastern Brazil. Journal of Tropical Ecology 10:483-508.

OLIVEIRA FILHO, A.T., CURI, N., VILELA, E.A. \& CARVALHO, D.A. 1997a. Tree species distribution along soil catenas in a riverside semideciduous forest in Southeastern Brazil. Flora 192:47-64. 
OLIVEIRA FILHO, A.T., MELLO, J.M. \& SCOLFORO, J.R.S. $1997 \mathrm{~b}$. Effects of past disturbance and edges on tree community structure and dynamics within a fragment of tropical semideciduous forest in south-eastern Brazil over a five-year period (1987-1992). Plant Ecology 131:45-66.

OLIVEIRA FILHO, A.T., CURI, N., VILELA, E.A. \& CARVALHO, D.A. 2001. Variation in tree community composition and structure with changes in soil properties within a fragment of semideciduous forest in south-eastern Brazil. Edinburgh Journal of Botany 58:139-158.

PALMER, M.W. 1991. Estimating species richness: the second-order jackknife reconsidered. Ecology 72:15121513.

PEREIRA, J.A.A., OLIVEIRAFILHO, A.T. \& LEMOS FILHO, J.P. 2007. Environmental heterogeneity and disturbance by humans control much of the tree species diversity of Atlantic montane forest fragments in SE Brazil. Biodiversity and Conservation (no prelo: artigo 9063, BIOC1721,24p.).

RESENDE, M., CURI, N. \& SANTANA, D.P. 1988. Pedologia e fertilidade do solo: interações e interpretações. Editora UFLA, Lavras.

RESENDE, M., CURI, N., REZENDE, S.B. \& CORRÊA, G.F. 1995. Pedologia: bases para distinção de ambiente. Núcleo de Estudo de Planejamento e Uso da Terra, Viçosa.
SCOLFORO, J.S., MELLO, J.M. 2006. Inventário Florestal, v. 1. Editora UFLA, Lavras.

SOUZA, J.S., ESPÍRITO-SANTO, F.D.B., FONTES, M.A.L., OLIVEIRAFILHO,A.T.\&BOTEZELLI,L.2003.Análise das variações florísticas e estruturais da comunidade arbórea de um fragmento de Floresta Semidecídua às margens do rio Capivari, Lavras-MG. Revista Árvore 27:185-206.

TER BRAAK, C.J.F. 1987. The analysis of vegetationenvironment relationship by canonical correspondence analysis. Vegetatio 69:69-77.

TER BRAAK, C.J.F. 1988. Canoco - a fortran program for canonical community ordinatin by (Partial) (Detrended) (Canonical) correspondence analysis and redundancy analysis, version 2.1. Technical report LWA-88-2 TNO, Wageningen.

TER BRAAK, C.J.F. 1995. Ordination. In Data analysis in community and landscape ecology (R.H.G. Jongman, C.J.F. Ter Braak \& O.F.R. Van Tongeren, eds.). Cambridge University Press, Cambrigde, p.91-173.

TER BRAAK, C.J.F. \& P. SMILAUER. 2002. CANOCO Reference manual and CanoDraw for Windows user's guide: Software for Canonical Community Ordination (version 4.5). Microcomputer Power, Ithaca.

VELOSO, H.P., RANGEL FILHO, A.L.R. \& LIMA, J.C. 1991. Classificação da vegetação brasileira adaptada a um sistema universal. IBGE, Rio de Janeiro.

ZAR, J.H. 1996. Biostatistical analysis. $3^{\text {rd }}$ ed., Prentice-Hall, New Jersey. 